\title{
Symbiotic Burkholderia Species Show Diverse Arrangements of nif/fix and nod Genes and Lack Typical High-Affinity Cytochrome cbb3 Oxidase Genes
}

\author{
Sofie E. De Meyer, ${ }^{1}$ Leah Briscoe, ${ }^{2}$ Pilar Martínez-Hidalgo, ${ }^{2}$ Christina M. Agapakis, ${ }^{2}$ \\ Paulina Estrada de-los Santos, ${ }^{3}$ Rekha Seshadri, ${ }^{4}$ Wayne Reeve, ${ }^{1}$ George Weinstock, ${ }^{5}$ Graham O'Hara, ${ }^{1}$ \\ John G. Howieson, ${ }^{1}$ and Ann M. Hirsch ${ }^{2,6}$ \\ ${ }^{1}$ Centre for Rhizobium Studies, Murdoch University, Western Australia, Australia; ${ }^{2}$ Dept. of Molecular, Cell and Developmental Biology, \\ UCLA, Los Angeles, CA, U.S.A.; ${ }^{3}$ Instituto Politécnico Nacional, Escuela Nacional de Ciencias Biológicas. Prol. Carpio y Plan de Ayala \\ s/n, Col. Santo Tomás, Del. Miguel Hidalgo, C.P. 11340, México; ${ }^{4}$ DOE Joint Genome Institute, Walnut Creek, CA, U.S.A.; ${ }^{5}$ The Jackson \\ Laboratory for Genomic Medicine, Farmington, CT, U.S.A; and ${ }^{6}$ The Molecular Biology Institute, UCLA, Los Angeles, CA, U.S.A.
}

Accepted 30 May 2016.

\begin{abstract}
Genome analysis of fourteen mimosoid and four papilionoid beta-rhizobia together with fourteen reference alpha-rhizobia for both nodulation (nod) and nitrogen-fixing (nif/fix) genes has shown phylogenetic congruence between $16 \mathrm{~S}$ rRNA/MLSA (combined 16S rRNA gene sequencing and multilocus sequence analysis) and nif/fix genes, indicating a free-living diazotrophic ancestry of the beta-rhizobia. However, deeper genomic analysis revealed a complex symbiosis acquisition history in the betarhizobia that clearly separates the mimosoid and papilionoid nodulating groups. Mimosoid-nodulating beta-rhizobia have nod genes tightly clustered in the nodBCIJHASU operon, whereas papilionoid-nodulating Burkholderia have nodUSDABC and nodIJ genes, although their arrangement is not canonical because the nod genes are subdivided by the insertion of nif and other genes. Furthermore, the papilionoid Burkholderia spp. contain duplications of several nod and nif genes. The Burkholderia nifHDKEN and fixABC genes are very closely related to those found in free-living diazotrophs. In contrast, nifA is highly divergent between both groups, but the papilionoid species nifA is more similar to alpha-rhizobia nifA than to other groups. Surprisingly, for all Burkholderia, the fixNOQP and fixGHIS genes required for $c b b 3$ cytochrome oxidase production and assembly are missing. In contrast, symbiotic Cupriavidus strains have fixNOQPGHIS genes, revealing a divergence in the evolution of two distinct electron transport chains required for nitrogen fixation within the beta-rhizobia.
\end{abstract}

Biological nitrogen fixation (BNF) by rhizobia has been studied intensively during the past century because this process supplies utilizable nitrogen $(\mathrm{N})$ for agriculture at little cost to the environment. For most of this period, rhizobia were classified as closely related species currently placed in the Alphaproteobacteria genera Azorhizobium, Bradyrhizobium, Ensifer, Mesorhizobium, Neorhizobium, and Rhizobium. This view changed more recently with the identification of Betaproteobacteria (Burkholderia tuberum

Corresponding author: S. E. De Meyer; E-mail: sofdemey@outlook.com

*The $\boldsymbol{e}$-Xtra logo stands for "electronic extra" and indicates that one supplementary figure and two supplementary tables are published online.

○ 2016 The American Phytopathological Society
$\mathrm{STM}^{\mathrm{T}}{ }^{\mathrm{T}}$, Burkholderia phymatum $\mathrm{STM} 15^{\mathrm{T}}$, and Cupriavidus taiwanensis LMG $19424^{\mathrm{T}}$ ) as nodulators of legumes (Chen et al. 2003a, 2005; Moulin et al. 2001). At first, the scientific community found the idea of Betaproteobacteria (beta-rhizobia) functioning as nitrogen-fixing symbionts in legume root nodules to be controversial, but Burkholderia and Cupriavidus species have been confirmed numerous times as the main microsymbionts for many mimosoid legumes (Gyaneshwar et al. 2011; Liu et al. 2012). Since then, research on nodulating Burkholderia species has proliferated (Gyaneshwar et al. 2011; Howieson et al. 2013; Lemaire et al. 2015b). Moreover, the research on the Brazilian mimosoidnodulating beta-rhizobia has shown a strong correlation between Burkholderia nodulation and the host legume's geographic distribution. B. caribensis (Chen et al. 2003b), B. diazotrophica (Sheu et al. 2013), B. mimosarum (Chen et al. 2006), B. nodosa (Chen et al. 2007), B. phymatum (Elliott et al. 2007b; Vandamme et al. 2002), B. sabiae (Chen et al. 2008), B. symbiotica (Sheu et al. 2012), and C. taiwanenis (Chen et al. 2001, 2003a) are reported to nodulate Mimosa species. Also, Bournaud et al. (2013) provide additional evidence of a growing diversity of mimosoid-nodulating Burkholderia species, including B. phenoliruptrix. However, Bontemps et al. $(2010 ; 2016)$ reported that the native Mimosa species of Mexico, which are distinct from the Brazilian species, are more likely to be nodulated by alpha-rhizobia than beta-rhizobia, although certain Burkholderia are known to nodulate $M$. occidentalis (Ormeño-Orrillo et al. 2012) and the widespread M. somnians and M. skinneri species in Mexico (Bontemps et al. 2016).

In contrast, papilionoid legume-nodulating Burkholderia species from the Cape Floristic Region (CFR) are not as well-studied as the mimosoid legume-nodulating bacteria, although progress has been made (Garau et al. 2009; Howieson et al. 2013; Lemaire et al. 2015b), especially for those species associated with the CFR-endemic papilionoids, namely members of the Crotalariae, Hypocalypteae, Phaseoleae, and Podalyrieae tribes (Beukes et al. 2013; Lemaire et al. 2015b, 2016). Many of these isolates also nodulate cowpea (Vigna unguiculata L.) and siratro (Macroptilium atropurpureum L.) (Angus et al. 2013; Elliott et al. 2007a). Several are closely related to B. tuberum, based on 16S rRNA analysis (Elliott et al. 2007a), and a number of these beta-rhizobia have been described as new species, including B. dilworthii (De Meyer et al. 2014), B. dipogonis (Sheu et al. 2015), B. rhynchosiae (De Meyer et al. 2013a), and $B$. sprentiae (De Meyer et al. 2013b). Of the South African strains, only B. tuberum and B. dipogonis have been investigated 
for their ability to form a symbiosis with mimosoid plants, which they failed to nodulate (Elliott et al. 2007a; Liu et al. 2014).

As for the alpha-rhizobia, the symbiosis between betarhizobia and their associated legumes also requires a specific communication process that includes the expression of nodulation (nod) and nitrogen fixation (nif, fix, and $f d x$ ) genes located in the genome of the microsymbiont. The nod genes are responsible for the synthesis of the Nod factor (NF), which triggers the initial plant responses for nodule development. The core nod genes (nodABC) encode enzymes for synthesizing the lipo-chitin backbone of the NF, whereas expression of additional nod genes results in a NF decorated with chemical substitutions, which are important for host specificity (Wang et al. 2012). However, little is known about the NF-encoding genes in the beta-rhizobia or of the structure of the Nod factors.

The essential BNF genes in beta-rhizobia are the same as those in alpha-rhizobia, but the exact mechanism of how BNF functions in the symbiotic Burkholderia spp. has not been elucidated. BNF is an ATP-dependent and highly energy-consuming process executed by the nitrogenase enzyme complex, which is composed of two main functional subunits, dinitrogenase reductase and dinitrogenase (Kneip et al. 2007). In the alpha-rhizobia, low nitrogen availability in the nodule environment leads to the activation of the transcriptional regulator nifA, which triggers additional nif gene expression needed for converting nitrogen gas into ammonium. Under microaerobic conditions, certain fix genes are also essential for nitrogen fixation. FixL, an oxygen-sensing membranebound protein, autophosphorylates and transfers a phosphoryl group to the two-component signal transduction regulator FixJ (Foussard et al. 1997). Genes directly regulated by FixJ include nifA, which regulates nifHDK, and the Crp/Fnr regulator fixK, which, when expressed, induces the transcription of fixNOQP and fixGHIS. The fixNOQP and fixGHIS genes are required for the production and assembly of $c b b 3$ cytochrome oxidase (Pitcher and Watmough 2004), an enzyme that is essential for many anaerobic biological processes, including anoxygenic photosynthesis and nitrogen fixation (Ekici et al. 2012). The $c b b 3$-encoded enzyme is thought to be an essential oxidase for symbiotic bacteria because it has a high oxygen affinity, and oxygen is present in low concentrations in the nodule environment. However, studies on Azorhizobium, Azotobacter, and Klebsiella spp. have revealed that an alternate oxidase, encoded by $c y t b d$, is also important for free-living $\mathrm{N}_{2}$-fixation (Juty et al. 1997; Kaminski et al. 1996; Kelly et al. 1990). Azorhizobium caulinodans, the Sesbania rostrata symbiont, utilizes both $c y t c b b 3$ and $c y t b d$ oxidases for $\mathrm{N}_{2}$-fixation (Kaminski et al. 1996). All currently known legume microsymbionts possess the $c b b 3$ cytochrome oxidase for nitrogen fixation. In addition to the $c b b 3$ genes, electron flow through the electron transport chain is mediated by the FixABC flavoproteins.

In this work, we investigated 29 betaproteobacterial genomes from both symbiotic and free-living diazotrophic bacteria as well as from representative alphaproteobacterial symbionts to understand i) the possible origin of symbiosis genes, ii) the structural organization of the symbiosis genes in the genome, iii) the amount and possible direction of horizontal gene transfer (HGT) of symbiotic genes, and iv) symbiotic specificity in the papilionoid-nodulating group of beta-rhizobia. We also show that the symbiotic and free-living diazotrophic Burkholderia spp., in contrast to Cupriavidus spp. and alpharhizobia, lack the genes required for $c b b 3$ cytochrome oxidase.

\section{RESULTS}

\section{Genome information and average nucleotide identity (ANI) analysis.}

In total, 29 Betaproteobacteria genomes were investigated for their symbiotic (nod) and nitrogen fixation (nif, fix) genes (Supplementary Table S1). The 14 mimosoid-nodulating strains originated from Brazil, China, French Guiana, Mexico, New Caledonia, Taiwan, Uruguay, and the United States, with the

Table 1. Genome-wide average nucleotide identity (gANI) values for the investigated Betaproteobacteria

\begin{tabular}{|c|c|c|c|c|c|}
\hline Genome & IMG ${ }^{\text {a genome no. }}$ & ANI clique no. & gANI/alignment fraction & Scaffold count & Size (Mbp) \\
\hline Burkholderia phenoliruptrix BR3459 & 2518645580 & 1630 & $98.77 / 0.80$ & 3 & 7.6 \\
\hline Burkholderia sp. strain CCGE1001 & 649633021 & 1630 & & 2 & 6.8 \\
\hline Burkholderia mimosarum LMG $23256^{\mathrm{T}}$ & 2513237083 & 35 & $99.48 / 0.88$ & 268 & 8.4 \\
\hline Burkholderia mimosarum STM3621 & 2513237082 & 35 & & 268 & 8.6 \\
\hline Burkholderia sp. strain WSM4176 & 2516653074 & 431 & $97.14 / 0.68$ & 13 & 9 \\
\hline Burkholderia tuberum STM678 ${ }^{\mathrm{T}}$ & 2501025500 & 431 & & 643 & 8.2 \\
\hline Burkholderia sp. strain CCGE1002 & 646564515 & 1516 & $98.04 / 0.80$ & 4 & 7.8 \\
\hline Burkholderia sp. strain JPY251 & 2515154122 & 1516 & & 122 & 8.6 \\
\hline Burkholderia silvatlantica PVA5 & 2501025501 & 1786 & $98.84 / 0.85$ & 491 & 7.7 \\
\hline Burkholderia silvatlantica SRMrh- $20^{\mathrm{T}}$ & 2501025504 & 1786 & & 519 & 8 \\
\hline Cupriavidus taiwanensis LMG $19424^{\mathrm{T}}$ & 644736347 & 1442 & $99.03 / 0.91$ & 3 & 6.4 \\
\hline Cupriavidus taiwanensis STM6018 & 2513237150 & 1442 & & 80 & 6.5 \\
\hline Burkholderia dilworthii WSM $3556^{\mathrm{T}}$ & 2508501124 & Singleton & N/A & 140 & 7.6 \\
\hline Burkholderia nodosa DSM 21604 & 2515154189 & Singleton & N/A & 114 & 9.6 \\
\hline Burkholderia phymatum STM815 & 642555112 & Singleton & N/A & 4 & 8.6 \\
\hline Burkholderia sp. strain UYPR1.413 & 2513237166 & Singleton & N/A & 336 & 10.3 \\
\hline Burkholderia sprentiae WSM5005 & 2510065045 & Singleton & N/A & 8 & 7.7 \\
\hline Burkholderia sp. strain CCGE1003 & 648028011 & Singleton & N/A & 2 & 7 \\
\hline Burkholderia sp. strain Ch1-1 & 2508501040 & Singleton & N/A & 4 & 8.7 \\
\hline Burkholderia sp. strain $\mathrm{H} 160$ & 642979355 & Singleton & N/A & 310 & 7.8 \\
\hline Burkholderia sp. strain JPY347 & 2515154123 & Singleton & N/A & 57 & 6.3 \\
\hline Burkholderia sp. strain JPY366 & 2526164713 & Singleton & N/A & 69 & 6.7 \\
\hline Burkholderia sp. strain WSM2230 & 2513237151 & Singleton & N/A & 33 & 6.3 \\
\hline Burkholderia sp. strain WSM2232 & 2508501125 & Singleton & N/A & 72 & 7.2 \\
\hline Burkholderia unamae MTI-641 ${ }^{\mathrm{T}}$ & 2501025502 & Singleton & N/A & 960 & 9.6 \\
\hline Burkholderia xenovorans $\mathrm{LB} 400^{\mathrm{T}}$ & 637000053 & Singleton & N/A & 3 & 9.7 \\
\hline Cupriavidus sp. strain AMP6 & 2524023212 & Singleton & N/A & 260 & 7.5 \\
\hline Cupriavidus sp. strain UYPR 2.512 & 2513237163 & Singleton & N/A & 365 & 7.8 \\
\hline Cupriavidus taiwanensis STM6070 & 2513237165 & Singleton & N/A & 107 & 6.7 \\
\hline
\end{tabular}

${ }^{\mathrm{a}} \mathrm{IMG}=$ Integrated Microbial Genomes database. 
majority isolated from Latin America. The four papilionoidnodulating strains originated from the Fynbos region on the west coast of South Africa, primarily out of a program searching for climate change-adapted legumes (Howieson et al. 2008).

Genome-wide (g)ANI was obtained for all Betaproteobacteria genomes, which identified six cliques and 16 singletons (Table 1). Clique 1 contains B. phenoliruptrix BR3459 and CCGE1001, which also show high (99.52\%) 16S rRNA sequence similarity with each other. Clique 2 comprises $B$. mimosarum strains LMG $23256^{\mathrm{T}}$ and STM3621. Clique 3 provides evidence that $B$. tuberum STM $678^{\mathrm{T}}$ and WSM4176 could belong to the same species, because their gANI value is 97.14 and they also share $99.79 \% 16 \mathrm{~S}$ rRNA sequence similarity. Clique 4 contains CCGE1002 and JPY251, both of which have B. tuberum STM678 ${ }^{\mathrm{T}}$ as their closest neighbor, with 98.55 and $99.04 \%$ 16S rRNA sequence similarity, respectively. Indeed, Mishra et al. (2012) described strain CCGE1002 as B. tuberum biovar mimosae and strain STM678 as B. tuberum biovar papilionoideae. However, the gANI value $(<90)$ indicates they might not belong to the same species. Clique 5 includes the $B$. silvatlantica strains (Angus et al. 2013; Perin et al. 2006), and clique 6 comprises the C. taiwanensis strains STM6018 and LMG $19424^{\mathrm{T}}$. Strain STM6070 was originally described as C. taiwanensis (Klonowska et al. 2012), but gANI analysis places this strain in a singleton and $16 \mathrm{~S}$ rRNA sequence similarity shows $C$. necator $\mathrm{N}-1^{\mathrm{T}}$ as its closest neighbor, with $99.13 \%$ similarity.

\section{Loss of symbiosis genes.}

Nodulation and nitrogen fixation genes were not detected in strains CCGE1001, CCGE1003, H160, JPY347, WSM2230, and WSM2232, although they were initially reported to nodulate and fix nitrogen with their original host (Ormeño-Orrillo et al. 2012; Walker et al. 2014a and b) (J. M. Tiedje personal communication). Therefore, these genomes were omitted from further analyses.

\section{nod genes.}

In total, 10 nod genes were investigated: $\operatorname{nod} A, \operatorname{nod} B, \operatorname{nod} C$, $\operatorname{nodD}, \operatorname{nodH}, \operatorname{nodI}, \operatorname{nodJ}, \operatorname{nod} S, \operatorname{nod} U$, and $\operatorname{nol} O$ (Figs. 1, 2, and 3 ). All genomes of the microsymbionts contained one copy of nodA. However, phylogenetic analysis revealed, with regard to symbiotic gene arrangement, that two distinct groups of betarhizobia exist. They correspond to the mimosoid-nodulating Burkholderia species and the papilionoid-nodulating group (Figs. 1 and 2). The mimosoid-nodulating species exhibit an almost canonical arrangement of nod and nif genes when compared with the organization of the symbiotic genes in alpha-rhizobia ( $R$. leguminosarum WSM2304 is the example used in Figure 1), albeit with several transposases, recombinases, insertion elements, and unknown genes within the nif/fix gene operons. In contrast, the nod genes of the papilionoidnodulating group are interrupted by not only transposases and other sequences but, also, by niflfix genes, resulting in a split in the canonical nodDABCIJ organization. We base this conclusion on the observation that both $\operatorname{nod} B$ and $\operatorname{nod} C$ each appear to exist as two copies of differently sized genes that occur a considerable distance apart on the chromosome. The larger copy of nodC (nodC1) is located adjacent to the nodIJ region, whereas the smaller copy, nodC2, is next to nodBA. This smaller sequence is very similar to the last $700 \mathrm{bp}$ of the larger nodC1 copy (Fig. 1). Further supporting the idea of a genomic rearrangement is the fact that, although a second $\operatorname{nod} B$ was detected in B. sprentiae WSM5005 ${ }^{\mathrm{T}}$ and Burkholderia sp. strain WSM4176 and was absent in B. dilworthii WSM3556 ${ }^{\mathrm{T}}$ (Fig. 1), B. tuberum STM678 ${ }^{\mathrm{T}}$, the comparable nodB, is likely to be a pseudogene, based on the presence of numerous stop codons (not shown). A nodB-like sequence (Fig. 1, yellow gene) was detected only by querying the intergenic space adjacent to nodC1. Also, the nodB similarity with the one found adjacent to nodAC is very low, based on MultAlin-based sequence analysis (Corpet 1988), and no highly similar hits were found using a National Center for Biotechnology Information (NCBI) BLAST search, although this nodB sequence is longer than the one found next to $\operatorname{nodAC}$.

Figures 1 and 2 highlight the relationships between the different genome sequences, by showing that the mimosoidnodulating beta-rhizobia are clearly separated from the papilionoid-nodulating beta-rhizobia. Although the nod $U$ genes in all beta-rhizobia appear to be well-conserved in terms of gene identity ( $\geq 74 \%)$ and orthology (Fig. 3), in contrast, the gene neighborhoods are not conserved (Fig. 1, Supplementary Fig. S1). The nolO gene (sometimes annotated as nod $U$ ) and nod $U$ both encode beta-1,4- $N$-acetylglucosamine oligosaccharide 3-O-carbamoyltransferase. Based on the low sequence identity between the papilionoid-nodulating Burkholderia spp. and the nonorthologous sequences in the other beta-rhizobia, nolO is likely to be a host-specific gene for the papilionoidnodulating group. Although highly conserved among papilionoid group members, the genes from other beta-rhizobia probed with nolO are only $\leq 40 \%$ identical to the comparable genes in the papilionoid-nodulating Burkholderia species. Because NodU and NolO are both in the NodU gene family, the pBLAST search picked up the nodU sequence. Moreover, the queried mimosoid-nodulating genes are not orthologous to nolO in the papilionoid group. Interestingly, nolO of the papilionoidnodulating group exhibits approximately $80 \%$ identity and

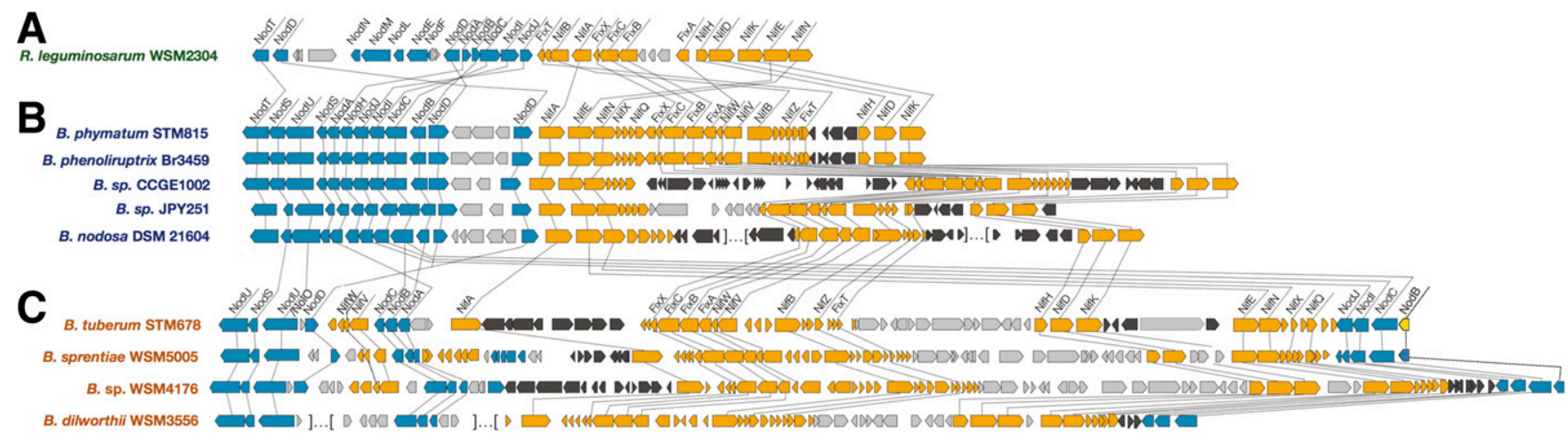

Fig. 1. Chromosomal arrangement of symbiotic genes. A, Example of an alpha-rhizobial species. Many alpha-rhizobia exhibit this organization of nod and nif genes. B, Mimosoid Burkholderia strains, and C, papilionoid Burkholderia strains. Blue indicates nod genes, orange indicates nif and fix genes, black are transposases, recombinases, and insertion elements as well as unknown genes. Gray represents nonsymbiosis-related genes. 
orthology to the genes of several alpha-rhizobia, namely Bradyrhizobium and Mesorhizobium spp. and Rhizobium etli (Fig. 3, shades of orange). A pBLAST against the NCBI database revealed 26 Bradyrhizobium sequences, 28 from Mesorhizobium, and a few Microvirga and Rhizobium strains with $n o l O$ DNA identities of $\geq 80 \%$ (data not shown). In addition, a second copy of nolO is present in the B. tuberum genome (with $99 \%$ identity) along with nod $S$, but the two genes are interrupted and flanked by transposases and recombinases (data not shown). This nolO gene is also $90 \mathrm{bp}$ shorter than the nolO gene in the nod operon (Fig. 1), due to the presence of insertional elements.

On the other hand, the host-specificity gene nodH, which adds a sulfate group to the NF, is absent in the papilionoidnodulating beta-rhizobia but present in the other beta-rhizobia and several of the alpha-rhizobia analyzed (Fig. 3). This nodH gene is likely to be a host-specificity gene, along with nod $U$, for the mimosoid-nodulating legumes. Finally, the nodIJ genes, which are part of the core nod genes and function as lipooligosaccharide transport system ATP-binding proteins, are highly conserved within the beta- and alpha-rhizobial strains (Fig. 3).

\section{nif genes.}

A broad spectrum of nif genes was investigated in this study (Figs. 1, 2, 4, 5, and 6). A nifH, nifD, and nifK phylogenetic analysis using 768-, 1,484-, and 1,411-bp gene sequences, respectively, positioned the free-living diazotrophic Burkholderia spp. closest to the papilionoid-nodulating Burkholderia spp. and clearly separated from the mimosoid-nodulating betarhizobia (Fig. 2). The alpha-rhizobia clustered as the outgroup, with the bradyrhizobia being closest to the beta-rhizobia.
In the free-living diazotrophic Burkholderia species, nifA and nifB are adjacent to each other (Fig. 4). However, in both the papilionoid- and mimosoid-nodulating Burkholderia strains, nifA and nifB are interrupted by other nif and fix genes. Among these interrupting genes, the nifZ gene sequence is duplicated in both the papilionoid-nodulating beta-rhizobia and the diazotrophic Burkholderia species, as well as in some of the mimosoid Burkholderia strains. Moreover, both Bradyrhizobium elkanii WSM2783 and Bradyrhizobium japonicum USDA 110 have a second copy of nifZ. Also, nifW but not always nif $V$ genes appear to be duplicated in the papilionoidnodulating beta-rhizobia and the free-living nitrogen fixers (Fig. 5). These clusters are not adjacent to each other but, rather, on opposite sides of nifA in the papilionoid strains (Fig. 4). The nifVl gene is homologous in all Burkholderia species but shows low gene identity with the alpha-rhizobial strains and the Cupriavidus strains, with the exception of Cupriavidus sp. strain UYPR2.512, which has $62 \%$ nifV1 gene identity and orthology to the genes of the papilionoid beta-rhizobia. We could find a second nifV2 (Fig. 5) in only three of the four papilionoid-nodulating Burkholderia genomes; none of the other bacteria have an additional copy of nifV.

Unlike nifB, the phylogeny of nifA does not follow the other nif gene phylogenies. The phylogenetic tree shows that the papilionoid-nodulating beta-rhizobia were nested within the alpha-rhizobia clade, and the free-living diazotrophic Burkholderia group were separate, but they are phylogenetically closer to the mimosoid-nodulating beta-rhizobia, which formed a tight wellsupported clade (Fig. 6). The nifA gene identity of the papilionoidnodulating strains compared with all other investigated strains

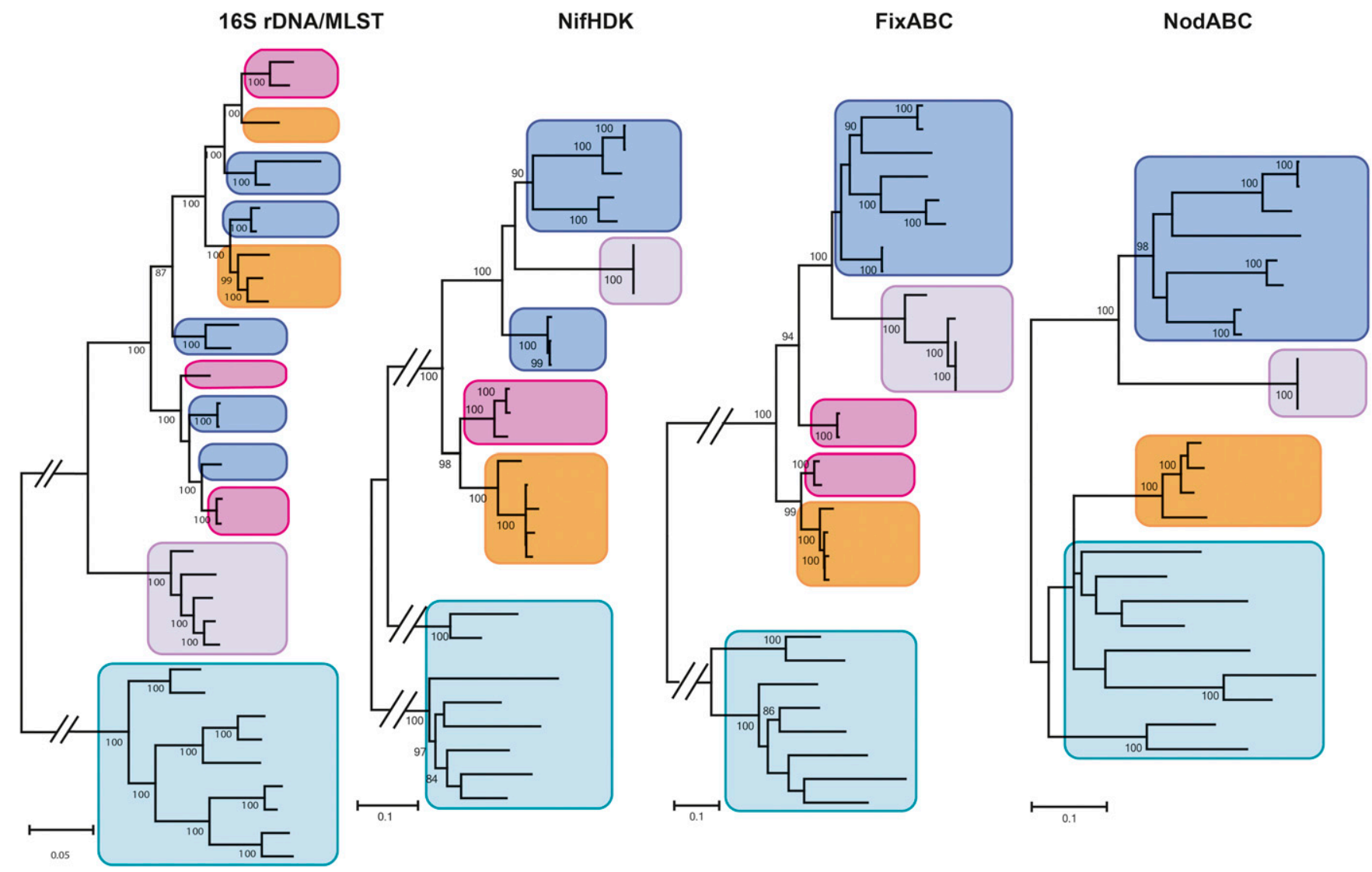

Fig. 2. Comparative maximum likelihood phylogenetic analysis using four different gene clusters. Colors indicate the different groups: blue-green: alpharhizobia, orange: papilionoid-nodulating Burkholderia strains; pink: diazotrophic Burkholderia strains; blue: mimosoid nodulating Burkholderia strains; and purple: Cupriavidus strains. Bootstrap values after 500 replicates are expressed as percentages; values less than $50 \%$ are not shown. The scale bar indicates the fraction of substitutions per site. 
was below or close to the $50 \%$ cut-off value except for Bradyrhizobium elkanii and Bradyrhizobium japonicum in the alpha-rhizobia, which showed 81 and $70 \%$ gene identity, respectively (Fig. 5).

Phylogenetic analysis of nifE and nifN revealed the presence of a single copy in each of the genomes (Fig. 5) and they showed the same clustering as identified for the nifH, nifD, and nifK genes (Fig. 2). However, in the mimosoid-nodulating betarhizobia, nifE, nifN, nifX, and nifQ are in an operon together with nifA, whereas in the papilionoid-nodulating beta-rhizobia, nifEN is positioned close to nifHDK (Figs. 1 and 4), albeit with transposase genes and other such elements in between them. However, for the free-living diazotrophic Burkholderia species, the nifHDK is almost adjacent to nifENXQ (Fig. 4).

Each of the nifB, nifZ, nif $X$ and nif $Q$ genes performs different functions in the nitrogen fixation process (Curatti et al. 2007). However, their phylogeny was identical to the nifHDK gene sequence phylogeny, such that the papilionoid-nodulating betarhizobia were closest to the free-living diazotrophic Burkholderia spp., the mimosoid-nodulating beta-rhizobia were a second branch, and the alpha-rhizobia made up the outgroup (data not shown).

\section{fix genes.}

In total, 13 fix genes were investigated: fixA, fix B, fix C, fix $G$, fixH, fixI, fixN, fixO, fixP, fixQ, fixS, fixT, and fixX (Supplementary Table S2). Genome analysis revealed the absence of both the fixNOQP and fixGHIS gene clusters in all Burkholderia strains, including both symbionts and free-living diazotrophs. Furthermore, several alpha-rhizobia contained multiple copies of these genes, whereas, for the Cupriavidus strains, only a single copy was present. Because an alternative high oxygen affinity cytochrome needs to be present in symbiotic and free-living diazotrophic Burkholderia strains, we searched the genomes for alternative cytochrome oxidases. All Burkholderia genomes harbored the genes for the high aeration cytochromes $a a 3$ and bo and the low aeration cytochrome $b d$ (data not shown). For B. tuberum, cytochrome bo genes were nested within the nif and fix gene clusters, and two cytochrome d gene operons, consisting of the genes $c y d A$ and $c y d B$, were found outside of the symbiotic region (data not shown).

Another set of fix genes required for $\mathrm{N}_{2}$-fixation is fix $A B C X$ Genome analysis revealed the presence of this gene cluster in all the genomes analyzed. Additionally, these genes exhibited similar phylogenies as the nifHDK gene cluster, with the alpha-rhizobia as the outgroup, the mimosoid Burkholderia and Cupriavidus strains together and quite distant from the papilionoid Burkholderia and free-living diazotrophic Burkholderia strains (Fig. 2).

\section{Other nitrogen fixation-related genes.}

Several genes embedded within the nif region, e.g., two subunits of a $4 \mathrm{Fe}-4 \mathrm{~S}$ ferredoxin iron-sulfur binding domaincontaining protein that were originally annotated as ferredoxin $(f d x)$ and hesB/yadR/yhf were positioned next to nifB (Fig. 4). The position of these genes is well conserved among the diazotrophic strains and all symbiotic strains. A nif-specific ferredoxin III was also detected next to nifQ in all the strains examined as well as a second gene annotated as a probable nitrogen fixation gene (Fig. 4, highlighted in yellow), which was adjacent to nifX.

\section{DISCUSSION}

Biological nitrogen fixation has been studied intensely, using two very different systems, the symbiotic $\mathrm{N}_{2}$-fixers and the freeliving diazotrophic $\mathrm{N}_{2}$-fixers. In the current study, we investigated 37 symbiosis and nitrogen-fixation genes in 43 bacterial genomes that included 14 mimosoid- and four papilionoid-nodulating betabacteria as well as five free-living diazotrophic beta-bacteria, 14 alpha-rhizobia, and six nonsymbiotic, nonfixing beta-bacteria.

The development of a mature $\mathrm{N}_{2}$-fixing symbiosis within a nodule requires the activation of a large number of nod, nif, fix, and $\mathrm{N}_{2}$ fixation-related genes at specific stages in the developmental process. The formation of a legume root nodule, in the majority of cases, is dependent on the presence of several microsymbiont nod genes, which encode proteins for Nod Factor (NF) production, transport, and regulation. All known

\begin{tabular}{|c|c|c|c|c|c|c|c|c|c|c|c|c|c|c|c|c|c|c|c|c|c|c|c|}
\hline & IMG Gene ID & 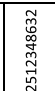 & 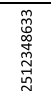 & 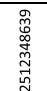 & 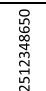 & 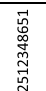 & 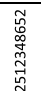 & 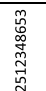 & 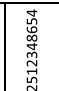 & 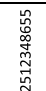 & 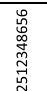 & 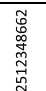 & 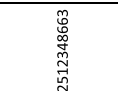 & 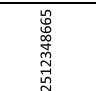 & 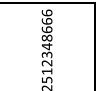 & 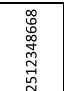 & 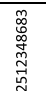 & 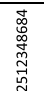 & 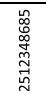 & 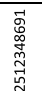 & 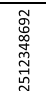 & 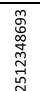 & 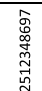 \\
\hline \multirow{5}{*}{$\begin{array}{c}\text { Papilionoid- } \\
\text { legume } \\
\text { nodulating } \\
\text { strains } \\
\end{array}$} & Gene & nifW1 & nifv1 & $n i f A$ & $f i x x$ & $f i x c$ & $f i x B$ & fixA & nifW2 & $\frac{i}{n i f 2}$ & $n i f B$ & $f d x$ & hesB/yadR/yfhF & nifz domain & nifz domain & nift/fixu & $\frac{i f H}{n i f H}$ & $n i f D$ & nifk & nife & nifN & $n i f x$ & nifQ \\
\hline & Bukholderia tuberum STM678 & 100 & 100 & 100 & 100 & 100 & 100 & 100 & 100 & 100 & 100 & 100 & 100 & 100 & 100 & 100 & 100 & 100 & 100 & 100 & 100 & 100 & 100 \\
\hline & Burkholderia sprentiae WSM5005 & $\underline{94}$ & $\underline{97}$ & $\underline{92}$ & $\underline{99}$ & $\underline{99}$ & $\underline{98}$ & $\underline{98}$ & $\underline{98}$ & $\underline{87}$ & $\underline{98}$ & $\underline{97}$ & $\underline{99}$ & $\underline{98}$ & $\underline{99}$ & $\underline{96}$ & 100 & $\underline{98}$ & $\underline{99}$ & 98 & 97 & 96 & 97 \\
\hline & Burkholderia sp. WSM4176 & $\underline{94}$ & $\underline{97}$ & $\underline{92}$ & 100 & $\underline{98}$ & $\underline{98}$ & $\underline{98}$ & $\underline{96}$ & $\underline{85}$ & $\underline{98}$ & $\underline{98}$ & $\underline{98}$ & $\underline{96}$ & 97 & 100 & 100 & $\underline{99}$ & $\underline{99}$ & 98 & 98 & 97 & 95 \\
\hline & Burkholderia dilworthii WSM3556 & 63 & $\underline{96}$ & $\underline{88}$ & $\underline{96}$ & $\underline{96}$ & $\underline{96}$ & $\underline{98}$ & $\underline{91}$ & n.d. & $\underline{93}$ & $\underline{92}$ & $\underline{95}$ & $\underline{93}$ & $\underline{95}$ & $\underline{96}$ & $\underline{99}$ & $\underline{98}$ & $\underline{98}$ & 94 & 95 & 94 & 91 \\
\hline \multirow{6}{*}{$\begin{array}{l}\text { Mimosoid- } \\
\text { legume } \\
\text { nodulating } \\
\text { strains }\end{array}$} & Burkholderia sp. CCGE1002 & 85 & 84 & 44 & 72 & 86 & 80 & 84 & 66 & n.d. & 70 & 87 & 54 & 68 & $n d$ & 7 & 91 & 8 & 8 & 7 & 7 & 76 & 57 \\
\hline & Burkholderia sp. JPY251 & 80 & 87 & 43 & 73 & $\frac{87}{87}$ & $\frac{80}{80}$ & 82 & 63 & n.d. & 73 & 90 & 32 & $\frac{60}{64}$ & n.d. & $\frac{10}{70}$ & $\frac{31}{91}$ & $\frac{00}{88}$ & $\frac{01}{87}$ & $\frac{15}{79}$ & $\frac{17}{77}$ & $\frac{10}{75}$ & $\frac{31}{58}$ \\
\hline & Burkholderia mimosarum LMG 23256 & 64 & $\underline{82}$ & $\underline{43}$ & $\underline{76}$ & $\underline{83}$ & $\underline{79}$ & 80 & 57 & n.d. & 73 & $\underline{84}$ & $\underline{53}$ & $\underline{70}$ & n.d. & n.d. & 91 & 88 & $\underline{87}$ & $\underline{80}$ & $7 \underline{76}$ & $\underline{64}$ & $\underline{52}$ \\
\hline & Burkholderia nodosa DSM 21604 & 60 & 81 & $\underline{43}$ & $\underline{76}$ & $\underline{84}$ & $\underline{77}$ & $\underline{79}$ & $\underline{58}$ & n.d. & 72 & $\underline{82}$ & $\underline{56}$ & 70 & n.d. & $\underline{65}$ & $\underline{90}$ & 87 & $\underline{86}$ & 80 & $\underline{76}$ & $\underline{66}$ & $\underline{53}$ \\
\hline & Burkholderia phenoliruptrix BR3459 & 84 & $\underline{86}$ & $\underline{44}$ & 80 & 86 & $\underline{81}$ & 87 & 60 & n.d. & 75 & $\underline{84}$ & $\underline{69}$ & 66 & $\underline{56}$ & $\frac{75}{75}$ & 90 & 89 & $\underline{87}$ & $\underline{84}$ & 79 & $\underline{71}$ & $\underline{61}$ \\
\hline & Burkholderia phymatum STM815 & 85 & 86 & 45 & 80 & 86 & 81 & 87 & 61 & n.d. & 74 & 84 & 63 & 64 & 56 & 75 & 90 & 89 & 87 & 84 & 79 & 73 & 61 \\
\hline \multirow{5}{*}{$\begin{array}{c}\text { Diazotrophic } \\
\text { Burkholderia } \\
\text { spp. }\end{array}$} & Burkholderia xenovorans LB400 & 66 & 74 & $\underline{42}$ & $\underline{96}$ & 95 & 94 & 95 & 92 & n.d. & 92 & 61 & $\underline{91}$ & 94 & 87 & 100 & 98 & 97 & $\underline{95}$ & 94 & 91 & 94 & 82 \\
\hline & Burkholderia unamae MTI-641 & 72 & 78 & $\underline{43}$ & 86 & $\underline{88}$ & 84 & 91 & 78 & n.d. & $\underline{82}$ & 92 & $\underline{75}$ & 86 & $\underline{75}$ & $\underline{88}$ & 97 & 94 & $\underline{92}$ & $\underline{89}$ & 84 & 89 & $\underline{69}$ \\
\hline & Burkholderia silvatlantica SRMrh-20 & 72 & 79 & $\underline{43}$ & 87 & $\underline{88}$ & 84 & 90 & 79 & n.d. & $\underline{82}$ & $\underline{92}$ & $\underline{73}$ & 85 & 75 & 88 & 95 & 94 & $\underline{92}$ & $\underline{89}$ & $\underline{85}$ & $\underline{88}$ & $\underline{68}$ \\
\hline & Burkholderia silvatlantica PVA5 & 71 & 79 & $\underline{43}$ & 87 & $\underline{88}$ & $\underline{84}$ & $\underline{91}$ & 79 & n.d. & $\underline{82}$ & $\underline{90}$ & $\underline{73}$ & 85 & $\underline{75}$ & $\underline{88}$ & 95 & $\underline{94}$ & $\underline{92}$ & $\underline{89}$ & $\underline{84}$ & 89 & 67 \\
\hline & Burkholderia vietnamiensis G4 & 62 & 75 & $\underline{42}$ & $\underline{86}$ & $\underline{88}$ & $\underline{82}$ & $\underline{86}$ & $\underline{69}$ & n.d. & $\underline{79}$ & $\underline{94}$ & $\underline{74}$ & $\underline{72}$ & $\underline{70}$ & $\underline{83}$ & $\underline{95}$ & $\underline{93}$ & $\underline{92}$ & $\underline{91}$ & $\underline{82}$ & $\underline{82}$ & $\underline{60}$ \\
\hline \multirow{3}{*}{$\begin{array}{l}\text { Cupriavidus } \\
\text { strains }\end{array}$} & Cupriavidus taiwanensis STM6070 & 75 & $\underline{41}$ & $\underline{43}$ & 75 & $\underline{82}$ & $\underline{76}$ & 82 & n.d. & n.d. & 36 & 76 & 34 & n.d. & n.d. & n.d. & 89 & 87 & 84 & 79 & 73 & 63 & n.d. \\
\hline & Cupriavidus sp. AMPG & 64 & 36 & $\underline{44}$ & $\underline{76}$ & $\underline{82}$ & $\underline{77}$ & $\underline{83}$ & $\underline{59}$ & n.d. & 36 & $\underline{77}$ & 34 & $\underline{71}$ & n.d. & n.d. & $\frac{89}{89}$ & $\frac{17}{87}$ & $\underline{84}$ & $\underline{79}$ & 71 & $\underline{62}$ & n.d. \\
\hline & Cupriavidus sp. UYPR2.512 & 71 & $\underline{62}$ & $\underline{41}$ & $\underline{74}$ & $\underline{82}$ & $\underline{76}$ & $\overline{85}$ & $\underline{60}$ & n.d. & 56 & $\overline{79}$ & 34 & $\underline{69}$ & n.d. & n.d. & $\overline{90}$ & 88 & $\underline{85}$ & 80 & $\underline{76}$ & $\overline{65}$ & n.d. \\
\hline \multirow{8}{*}{ Rhizobiaceae } & & & & & & & & & & & & & & & & & & & & & & & \\
\hline & Rhizobium tropici CIAT899 & 42 & 36 & 50 & $\frac{46}{60}$ & 57 & $\frac{65}{62}$ & $\frac{65}{61}$ & $\underline{42}$ & n.d. & 36 & $\frac{65}{60}$ & 38 & $\frac{54}{65}$ & n.d. & $\frac{63}{67}$ & $\frac{81}{20}$ & $\underline{73}$ & $\underline{59}$ & $\frac{66}{67}$ & 50 & 51 & $\frac{51}{20}$ \\
\hline & Rhizobium etli CFN 42, DSM 11541 & 38 & n.d. & $\underline{54}$ & $\underline{53}$ & $\underline{58}$ & $\underline{62}$ & 64 & 42 & n.d. & $\underline{31}$ & 60 & 37 & $\underline{65}$ & n.d. & $\underline{67}$ & $\underline{82}$ & $\underline{73}$ & $\underline{58}$ & $\underline{67}$ & $\underline{50}$ & $4 \underline{46}$ & $\underline{39}$ \\
\hline & Bradyrhizobium elkanii WSM2783 & 45 & 47 & $\underline{81}$ & $\underline{56}$ & $\underline{63}$ & $\underline{64}$ & $\underline{64}$ & $\underline{44}$ & n.d. & $\underline{50}$ & $\underline{85}$ & 31 & $\underline{64}$ & $\underline{56}$ & $\underline{61}$ & $\underline{93}$ & $\underline{84}$ & $\underline{68}$ & $\overline{73}$ & $\underline{56}$ & $\underline{68}$ & $\underline{46}$ \\
\hline & Bradyrhizobium japonicum USDA 110 & 42 & 33 & $\underline{70}$ & $\underline{48}$ & $\underline{59}$ & 64 & 60 & 45 & n.d. & 35 & $\underline{70}$ & 36 & $\underline{62}$ & 31 & $\underline{55}$ & 87 & 82 & $\underline{67}$ & $\underline{72}$ & 57 & $\underline{68}$ & 37 \\
\hline & Rhizobium phaseoli Ch24-10 & 38 & 30 & $\underline{54}$ & $\underline{53}$ & $\underline{58}$ & $\underline{62}$ & 64 & $\underline{42}$ & n.d. & 31 & $\underline{60}$ & 41 & 65 & n.d. & 67 & 82 & $\underline{77}$ & $\underline{58}$ & $\underline{67}$ & 50 & 45 & $\underline{39}$ \\
\hline & Methylobacterium nodulans ORS 2060 & 40 & 47 & $\underline{52}$ & $\underline{47}$ & $\underline{59}$ & $\underline{61}$ & $\underline{62}$ & $\underline{43}$ & n.d. & $\underline{49}$ & $\underline{70}$ & 40 & $\underline{54}$ & n.d. & $\underline{60}$ & 85 & $\underline{72}$ & $\underline{61}$ & $\underline{64}$ & $\underline{51}$ & $\underline{45}$ & $\underline{40}$ \\
\hline & Microvirga sp. BSC39 & n.d. & 35 & 48 & n.d. & n.d. & 33 & 31 & n.d. & n.d. & 37 & n.d. & 32 & n.d. & n.d. & n.d. & n.d. & n.d. & n.d. & n.d. & n.d. & n.d. & n.d. \\
\hline
\end{tabular}

Fig. 3. Nodulation (nod) genes investigated, including host specific, regulatory, and common nod genes. The third rows names nod genes identified in each strain (left column) following comparison with the Burkholderia tuberum STM678 ${ }^{\mathrm{T}}$ gene. Each gene family member is depicted by a color family: papilionoidnodulating Burkholderia strains, orange; mimosoid-nodulating Burkholderia strains, blue; Cupriavidus strains, purple; and alpha-rhizobia, blue-green. Any gene that is $\geq 50 \%$ identical to the $B$. tuberum query gene is indicated by an orange color; the darker the color, the greater the identity. Genes with an identity $<50 \%$ are marked in the color of the family they belong to. Genes not detected (n.d.) are colored gray. 
NF share the same chitin-like $N$-acetyl glucosamine oligosaccharide backbone but differ in backbone length and additional NF modifications, many of which mediate host specificity (Perret et al. 2000; Wang et al. 2012). Burkholderia NFs are so far unknown, but the genome analysis presented here provides insights into the potential NF structures of mimosoid and papilionoid beta-rhizobia. The mimosoid beta-rhizobia have a single copy of nod genes arranged in the operon nodBCIJHASU (Fig. 1), which differs from the canonical arrangement of the typical alpha-rhizobial nod genes (nodDABCIJ) (Fig. 1A). Some alpha-rhizobia may lack nodU or nodH or may have a large number of additional nod, nol, and noe genes for modifying host specificity. In contrast, the papilionoid beta-rhizobia nod genes seem simpler; the genes, like Bradyrhizobium and Mesorhizobium spp. seem to be chromosomal, show evidence for duplicate $n o d B$ and nodC genes, and have neither nodH (Fig. 3) nor noeE (data not shown). The presence of more than one $\operatorname{nodB}$ and $\operatorname{nod} C$ in these genomes is related to the insertion of nif genes within the nod operon, and the lack of nodH (and noeE) indicates that papilionoid beta-rhizobial NFs are not sulfated. On the other hand, the presence of nodSU and nolO indicates that methyl and carbamoyl groups are added to the core NF. Both NodU and NolO add carbomyl groups on the glucosamine residue at the nonreducing end to alpha-rhizobial NF (Broughton et al. 2000)

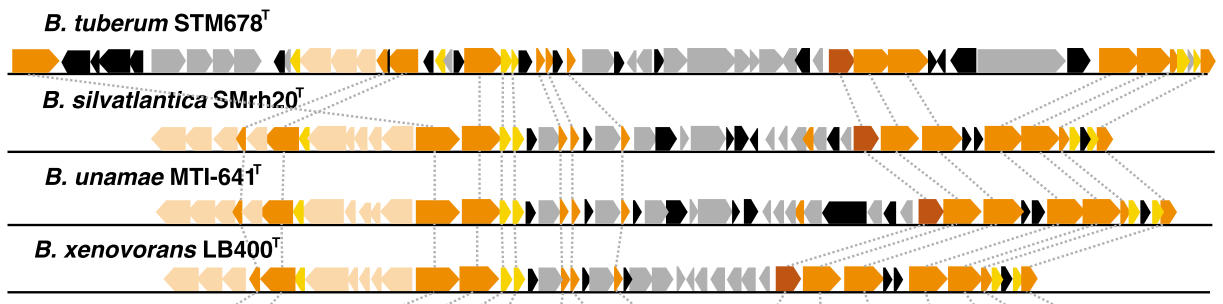

\begin{tabular}{|c|c|c|c|c|c|c|c|c|c|c|c|c|c|c|}
\hline $\mathrm{W}$ & & 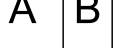 & $f d x$ & \multicolumn{2}{|c|}{ 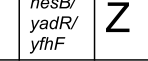 } & $Z$ & $\mathrm{~T}$ & $\mathrm{H}$ & D & $\mathrm{K}$ & E & $\mathrm{N}$ & X & Q \\
\hline
\end{tabular}

Fig. 4. Detailed niflfix region in papilionoid and free-living diazotrophic Burkholderia strains. Light orange indicates fix genes; dark orange indicates nif genes; yellow indicates nitrogen fixation-related genes; black are transposases, recombinases, and insertion elements as well as unknown genes, and gray represents nonsymbiosis-related genes. The map was aligned to nifB. The nifH is colored bronze to indicate the start of the nitrogenase operon.

\begin{tabular}{|c|c|c|c|c|c|c|c|c|c|c|c|c|}
\hline & Category & Host & ecific $n$ & od genes & Regul. & & & $\operatorname{mon} n$ & genes & & & CCGE1002 \\
\hline & IMG Gene ID & $\begin{array}{l}\stackrel{\sim}{\sim} \\
\stackrel{\infty}{\infty} \\
\stackrel{D}{\sim} \\
\stackrel{\sim}{\sim} \\
\stackrel{\sim}{N}\end{array}$ & 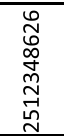 & 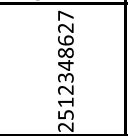 & 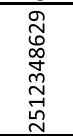 & 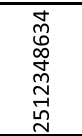 & $\begin{array}{l}\stackrel{\text { n }}{\tilde{N}} \\
\stackrel{\infty}{\infty} \\
\stackrel{+}{N} \\
\stackrel{\sim}{\sim} \\
\stackrel{\sim}{N}\end{array}$ & 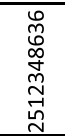 & 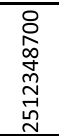 & 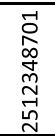 & 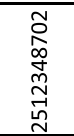 & 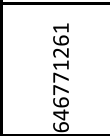 \\
\hline & Gene & $\operatorname{nod} U$ & nods & nolO/nodU & $\operatorname{nod} D$ & $\operatorname{nod} C 2$ & nodB & $\operatorname{nod} A$ & nodl & nodJ & $\operatorname{nod} C 1$ & nodH \\
\hline Papilionoid- & Burkholderia tuberum STM678 & 100 & 100 & 100 & 100 & 100 & 100 & 100 & 100 & 100 & 100 & n.d. \\
\hline legume & Burkholderia sp. WSM4176 & $\underline{99}$ & 98 & $\underline{98}$ & 94 & 90 & $\underline{94}$ & $\underline{98}$ & $\underline{98}$ & $\underline{96}$ & $\underline{87}$ & n.d. \\
\hline nodulating & Burkholderia sprentiae WSM5005 & $\underline{99}$ & $\underline{97}$ & $\underline{98}$ & 93 & 89 & $\underline{95}$ & $\underline{99}$ & $\underline{96}$ & $\underline{97}$ & $\underline{88}$ & n.d. \\
\hline strains & Burkholderia dilworthii WSM3556 & 98 & 94 & $\underline{96}$ & 99 & 79 & 94 & 98 & $\underline{96}$ & $\underline{94}$ & 89 & n.d. \\
\hline & Burkholderia phenoliruptrix BR3459 & $\underline{81}$ & 67 & $\overline{40}$ & 70 & 76 & $\underline{60}$ & $\overline{73}$ & $\underline{\overline{71}}$ & $\underline{77}$ & $\underline{\overline{70}}$ & $\underline{72}$ \\
\hline & Burkholderia phymatum STM815 & $\underline{80}$ & 66 & 39 & 69 & 76 & $\underline{60}$ & $\underline{73}$ & $\underline{70}$ & $\underline{77}$ & $\underline{70}$ & $\underline{69}$ \\
\hline & Burkholderia sp. CCGE1002 & $\underline{76}$ & 65 & 40 & $\underline{71}$ & 63 & $\underline{57}$ & $\underline{75}$ & $\underline{72}$ & $\underline{79}$ & $\underline{67}$ & $\overline{100}$ \\
\hline IVIImosold- & Burkholderia sp .JPY251 & $\underline{76}$ & 69 & 40 & $\underline{72}$ & 63 & $\underline{56}$ & $\underline{75}$ & $\underline{74}$ & $\underline{79}$ & $\underline{66}$ & $\underline{94}$ \\
\hline legume & Burkholderia sp. JPY366 & $\overline{75}$ & 71 & 40 & $\underline{68}$ & 71 & $\overline{72}$ & $\underline{70}$ & $\overline{71}$ & $\underline{76}$ & $\overline{71}$ & $\underline{66}$ \\
\hline nodulating & Burkholderia sp. UYPR1.413 & $\underline{75}$ & 66 & 39 & $\underline{66}$ & 75 & $\underline{58}$ & $\underline{71}$ & $\underline{73}$ & $\underline{76}$ & $\underline{75}$ & 64 \\
\hline & Burkholderia nodosa DSM 21604 & $\underline{75}$ & 64 & 29 & $\overline{68}$ & 72 & $\underline{60}$ & $\underline{72}$ & $\underline{73}$ & $\underline{79}$ & $\underline{72}$ & $\underline{67}$ \\
\hline & Burkholderia mimosarum STM3621 & $\overline{74}$ & 69 & 40 & 68 & 74 & $\underline{62}$ & $\underline{71}$ & $\overline{71}$ & $\underline{77}$ & $\overline{73}$ & $\underline{69}$ \\
\hline & Burkholderia mimosarum LMG 23256 & $\overline{74}$ & 69 & 39 & 68 & 74 & $\underline{62}$ & $\underline{71}$ & $\overline{71}$ & $\underline{77}$ & $\overline{73}$ & $\underline{69}$ \\
\hline & Cupriavidus sp. UYPR2.512 & $\underline{78}$ & $\underline{64}$ & 33 & 68 & 69 & $\underline{59}$ & $\underline{68}$ & $\underline{67}$ & $\underline{76}$ & $\underline{66}$ & $\underline{69}$ \\
\hline & Cupriavidus sp. AMP6 & $\overline{76}$ & $\overline{62}$ & 29 & 69 & 63 & $\overline{57}$ & $\underline{69}$ & $\underline{66}$ & $\overline{75}$ & $\underline{67}$ & $\underline{65}$ \\
\hline Cupriavidus & Cupriavidus taiwanensis LMG 19424 & $\underline{76}$ & $\underline{61}$ & 40 & 69 & 68 & $\underline{59}$ & $\underline{68}$ & $\underline{66}$ & $\underline{75}$ & $\underline{67}$ & $\underline{65}$ \\
\hline & Cupriavidus taiwanensis STM6018 & $\overline{76}$ & $\overline{61}$ & 40 & 69 & 68 & $\overline{59}$ & $\overline{68}$ & $\overline{66}$ & $\overline{75}$ & $\overline{67}$ & $\overline{65}$ \\
\hline & Cupriavidus taiwanensis STM6070 & $\overline{76}$ & $\overline{61}$ & 40 & 69 & 68 & $\overline{59}$ & $\overline{68}$ & $\overline{66}$ & $\overline{75}$ & $\overline{67}$ & $\overline{65}$ \\
\hline & Bradyrhizobium elkanii USDA 76 & $\underline{74}$ & 61 & $\underline{81}$ & $\underline{78}$ & 74 & $\underline{71}$ & $\underline{67}$ & $\underline{68}$ & $\underline{77}$ & $\underline{77}$ & n.d. \\
\hline & Bradyrhizobium japonicum USDA 6 & $\overline{74}$ & 59 & $\overline{79}$ & $\underline{75}$ & 71 & $\underline{70}$ & $\overline{72}$ & $\underline{67}$ & $\underline{76}$ & $\underline{71}$ & n.d. \\
\hline & Ensifer arboris LMG 14919 & $\underline{75}$ & 69 & 39 & $\underline{72}$ & 78 & $\underline{71}$ & $\overline{73}$ & $\underline{77}$ & $\underline{80}$ & $\underline{72}$ & $\underline{60}$ \\
\hline Phizohigrege & Ensifer meliloti 1021 & n.d. & n.d. & 39 & $\underline{73}$ & 70 & $\underline{67}$ & $\underline{64}$ & $\underline{73}$ & $\underline{77}$ & $\underline{68}$ & $\underline{59}$ \\
\hline Rhizobiaceae & Mesorhizobium australicum WSM2073 & $\underline{69}$ & 47 & $\underline{80}$ & $\underline{71}$ & 77 & $\underline{66}$ & $\underline{70}$ & $\underline{72}$ & $\underline{76}$ & $\underline{71}$ & $\underline{58}$ \\
\hline & Mesorhizobium loti R7A & n.d. & 65 & $\underline{81}$ & $\underline{76}$ & 72 & $\underline{70}$ & $\underline{73}$ & $\underline{73}$ & $\underline{78}$ & $\underline{71}$ & 24 \\
\hline & Rhizobium etli CFN 42, DSM 11541 & 61 & 71 & $\overline{75}$ & $\overline{73}$ & 73 & $\overline{66}$ & $\overline{70}$ & $\overline{74}$ & $\overline{77}$ & $\overline{71}$ & n.d. \\
\hline & Rhizobium leguminosarum bv. trifolii WSM1325 & n.d. & 46 & $\overline{\text { n.d. }}$ & $\underline{69}$ & 75 & $\underline{63}$ & 67 & 70 & $\overline{73}$ & 67 & n.d. \\
\hline
\end{tabular}

$\underline{\text { underline represents orthologous (bidirectional hit) }}$

\section{\begin{tabular}{lllll}
$90-100$ & $80-89$ & $70-79$ & $60-69$ & $50-59$ \\
\hline
\end{tabular}}

Fig. 5. Nitrogen fixation genes investigated, including nif, fix, and nitrogen fixation-related genes. The genes named were identified in each strain (left column) following a comparison with a Burkholderia tuberum STM678 gene. Each gene family member is depicted by a color family: papilionoid-nodulating Burkholderia strains, orange; mimosoid-nodulating Burkholderia strains, blue; free-living diazotrophic Burkholderia strains, pink; Cupriavidus strains, purple; and alpha-rhizobia, blue-green. Any gene that is $\geq 50 \%$ identical to the $B$. tuberum query gene is indicated by an orange color; the darker the color, the greater the identity. Genes with an identity $<50 \%$ are marked in the color of the family they belong to. Genes not detected (n.d.) are colored gray. 
and, based on our sequence analysis, these same substitutions are likely to be present on the NF in $B$. tuberum. Furthermore, apart from nodU, nolO, and nodS, no other host-specific nod genes occur in the papilionoid beta-rhizobia, which suggests that the NFs of this group of bacteria may be similar to those reported for Burkholderia tuberum (previously named "Bradyrhizobium aspalathi"), which was isolated from Aspalathus linearis (Boone et al. 1999; Elliott et al. 2007a).
The nodABC gene phylogenetic analysis shows a clear distinction between the mimosoid and papilionoid beta-rhizobia, as suggested in previous studies (Bontemps et al. 2010; Gyaneshwar et al. 2011). Within the mimosoid beta-rhizobial branch, the $\operatorname{nod} A, \operatorname{nod} B$, and $\operatorname{nod} C$ genes seem to have been acquired all at once, as indicated by their monophyletic origin and their presence on a symbiotic plasmid (Fig. 2). This is supported by previous work, which indicated the acquisition of

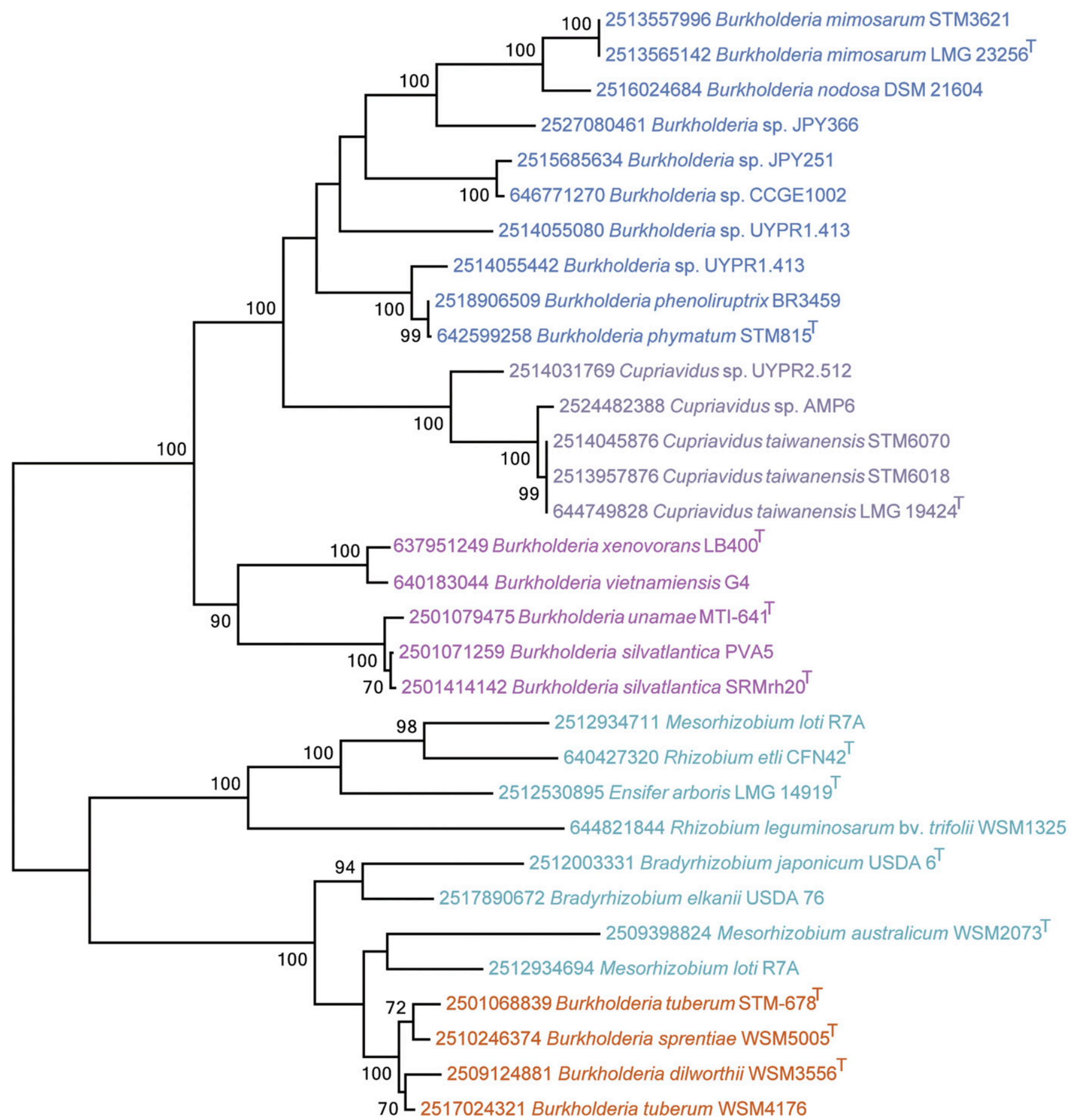

0.1

Fig. 6. Maximum likelihood nifA phylogenetic tree based on 1,888-bp gene alignment. Colors indicate the different groups: alpha-rhizobia, blue-green; papilionoid nodulating Burkholderia strains, orange; diazotrophic Burkholderia strains, pink; mimosoid nodulating Burkholderia strains, blue; and Cupriavidus strains, purple. Bootstrap values after 500 replicates are expressed as percentages and values less than $50 \%$ are not shown. The scale bar indicates the fraction of substitutions per site. The IMG (Integrated Microbial Genomes database) gene identification number is mentioned before the species name. 
nod genes by the mimosoid Burkholderia spp. and, then, subsequent transfer to Cupriavidus spp. (Bontemps et al. 2010; Parker 2015). By contrast, the papilionoid beta-rhizobia seem to have acquired these genes from a different source, because they form a subcluster within the alpha-rhizobial clade, indicating a close relationship between these two groups (Fig. 2). This finding might indicate an old acquisition event. Moreover, numerous transposase genes, integrase genes, and insertion elements reside within the symbiotic gene cluster in the papilionoid beta-rhizobia, resulting in the $\operatorname{nodB}$, and $\operatorname{nod} C$ genes being interrupted and also in various gene duplications. Lessie and colleagues (1996) showed that insertion elements promoted genomic rearrangement in B. cepacia, enabling this species, which like the environmental species studied here, has to adapt rapidly in terms of physiology and biochemistry to changes in the environment. Moreover, like B. cepacia, the symbiotic and environmental Burkholderia species have large genomes consisting of multiple replicons (Chen et al. 2003b; Martínez-Aguilar et al. 2008) and insertion elements (this study). Genomic replacement and the movement of various elements may promote the expression of symbiotic genes in the papilionoid beta-rhizobia in a similar manner to that observed for B. cepacia with regard to expression of genes for the degradation of xenobiotics (Lessie et al. 1996).

The question of which species was the donor of nod and nif genes and which was the recipient in this process is complicated by the presence of numerous mobile elements within the symbiotic islands of the papilionoid beta-rhizobia and the varied relationships between the symbiotic and diazotrophic Burkholderia species. The Burkholderia species that we investigated were grouped according to habitat (symbiotic versus nonsymbiotic) and host (mimosoid versus papilionoid). These groups are spread across the phylogeny in the $16 \mathrm{~S}$ rRNA/MLST (combined $16 \mathrm{~S}$ rRNA gene sequencing and multilocus sequence typing) tree, indicating that HGT of symbiosis genes would have occurred after divergence of the different phylogenetic lineages (Fig. 2). Additionally, these beta-rhizobia seem to have a complex acquisition history of their symbiotic genes, as supported by a recent study (Lemaire et al. 2015a). However, Mimosa-nodulating beta-rhizobia have distinct nod, nif, and fix genes, indicating these might have been obtained from an unknown ancestral source and diverged separately from the other groups (Fig. 2). In contrast, the papilionoid-nodulating Burkholderia spp. have both alpharhizobia-like $\operatorname{nod} A, \operatorname{nod} B$, and $\operatorname{nod} C$ and beta-rhizobia-like nodI and nodJ genes. The nodIJ gene phylogeny analysis indicates a single acquisition event in the beta-rhizobia, demonstrating two independent nod gene acquisitions in the papilionoid Burkholderia. A similar analysis led Aoki et al. (2013) to state that the nodI and nodJ gene sequence originated from gene duplication in the Betaproteobacteria, followed by a transfer to the Alphaproteobacteria and not the other way around. However, Lemaire et al. (2015a) did not observe HGT between the alpha- and beta-rhizobia investigated in their study. Our results support HGT between alpha- and beta-rhizobia, but additional research is necessary to understand the direction and frequency. On the other hand, some of the papilionoid- and mimosoid-nodulating Burkholderia nif genes exhibit strong homology based on gene identity with free-living diazotrophic nif genes (nifH, nifD, nifK, nifE, nifN), whereas others, nifA and nifVW, do not. Our results, thus, highlight the complex origin of symbiosis genes in the beta-rhizobia and their organization within the genome. In addition, the complete loss of symbiosis genes has been discovered in a number of the beta-rhizobial genomes investigated (López-Guerrero et al. 2012; Ormeño-Orrillo et al. 2012). The mechanisms that drive the gain or loss of the symbiotic genes are not known to date.

Lastly, we discovered the complete absence of the essential $c b b 3$ cytochrome oxidase mechanism (fixNOQPGHIS) in all
Burkholderia genomes investigated but found the alternative bd cytochrome in Burkholderia symbionts and diazotrophs. FixN, fixO, fix $Q$, fixP, fixG, fixH, fixI, and fixS genes are responsible for the production and assembly of the $c b b 3$ cytochrome oxidase (Pitcher and Watmough 2004). Homologous $c b b 3$ cytochrome oxidase genes are present inmembers of genera Brucella, Caulobacter, Campylobacter, Helicobacter, Neisseria, Pseudomonas, Ralstonia, and Vibrio, suggesting this oxidase is required for the successful colonization of one or both anoxic or micro-oxic tissues (Cosseau and Batut 2004; Parkhill et al. 2000; Pitcher and Watmough 2004). However, studies on Azorhizobium caulinodans single mutants in cytcbb3 or cytbd showed that they were still able to fix nitrogen symbiotically, whereas $c y t c b b 3$ and $c y t d b$ double mutants lacked symbiotic fixation ability (Kaminski et al. 1996). Similar findings were discovered in the diazotrophs Azotobacter vinelandii and Klebsiella pneumonia, emphasizing the importance of the cytbd system in nitrogen fixation (Juty et al. 1997; Kaminski et al. 1996; Kelly et al. 1990). Our genome analysis revealed the presence of the $c y t b d$ system in all investigated genomes. Their gene products could, therefore, be important as an alternative energy source for the $\mathrm{N}_{2}$-fixation process or for protecting it from $\mathrm{O}_{2}$ inhibition.

In addition to the FixN, fixO, fix $Q$, fixP, fixG, fixH, fixI, and fix $S$ genes, another set of fix genes (fix $A B C X)$ is important for $\mathrm{N}_{2}$-fixation. According to previous studies, FixAB shows similarity to an electron transfer flavoprotein and FixCX to a ubiquinone oxidoreductase involved in electron transfer (Arigoni et al. 1991; Tsai and Saier 1995). More recently, it has been confirmed that FixA, FixB, FixC, and FixX proteins are involved in the electron transfer pathway dedicated to the generation of reductant for nitrogenase (Edgren and Nordlund 2004). Our fix $A B C$ gene phylogenetic analysis suggests that both the papilionoid and mimosoid beta-rhizobia have acquired these genes from a free-living diazotrophic ancestor (Fig. 2). Moreover, the papilionoid beta-rhizobia's closest relative seems to be $B$. xenovorans, whereas the mimosoid beta-rhizobia share similarity with $B$. silvatlantica and B. unamae.

The congruence between the 16S rRNA/MLST and niflfix genes suggests that the beta-rhizobia were free-living diazotrophs before acquiring nodulation ability (Bontemps et al. 2010; Chen et al. 2003b; Elliott et al. 2007a; Gyaneshwar et al. 2011). This hypothesis is also consistent with the ability of B. phymatum and $B$. tuberum to fix nitrogen ex planta (Elliott et al. 2007b). However, the nifA results suggest an additional exchange with the alpha-rhizobia, supporting previous reports suggesting the possible transfer of nif genes from beta- to alpha-rhizobia (Bontemps et al. 2010). Thus, two separate nif gene acquisition events seem to have taken place in the beta-rhizobia, one acquisition from the freeliving diazotrophic Burkholderia spp., as indicated by nifHDKEN, and one from the alpha-rhizobia (nifA). Additionally, nifZ is duplicated in the papilionoid Burkholderia spp., the free-living diazotrophic Burkholderia, and in some of the mimosoid Burkholderia spp. and alpha-rhizobia but not in Cupriavidus spp. (Fig. 5). These inferences are based on a limited sample size and also on unfinished genome sequences, but with better sequencing technology and the sequencing of additional beta-rhizobial genomes, firmer conclusions about Burkholderia symbiotic genes will be forthcoming.

\section{MATERIALS AND METHODS}

\section{Selection of strains.}

Four groups of Betaproteobacteria were investigated: mimosoidnodulating Burkholderia strains, papilionoid-nodulating Burkholderia strains, Cupriavidus strains, and free-living diazotrophic strains. In addition, 14 Alphaproteobacteria strains were also included as reference rhizobia for comparison. 


\section{ANI analysis.}

ANI analysis was carried out by calculating the bidirectional gANI and alignment fraction (AF) between all genomes (Varghese et al. 2015). These computations included the identification of orthologous genes with $70 \%$ or more identity as a filter, and the length of these genes was used to compute AF, while the percent identity was used to compute gANI. Furthermore, those genome pairs that have at least a gANI of 96.5 and an AF of 60 to each other were used as input pairs for clustering, in which maximal cliques were identified using the Bron-Kerbosch algorithm. For more information about the tool and its application, see Varghese et al. (2015) and the Joint Genome Institute (JGI) website.

\section{Sequence search, phylogenetic analysis,} and congruence tests.

BLASTP search $\left(E=1 \mathrm{e}^{-5}\right)$ was performed, using the protein sequences of nod, nif, and fix genes from the Alphaproteobacteria reference strains to find putative homologs in the JGI IMG (Integrated Microbial Genomes) database, which includes the GEBA-RNB (Genomic Encyclopedia for Bacteria and Archaea-Root Nodule Bacteria) initiative that encompasses genome sequences of 107 rhizobial strains isolated from various locations around the world (Reeve et al. 2015). Moreover, the NCBI database was also queried the NCBI BLAST database.

Sequence alignment, alignment editing, and phylogenetic analyses were performed using MEGA 6.06 (Tamura et al. 2013). Phylogenetic trees were constructed, using the maximum likelihood reconstruction method (Felsenstein 1981) and applying the model resulting from the MEGA model test. The strength of each topology was verified using 500 bootstrap replications. The possibility of concatenating several gene sequences was investigated using the congruence tests (tree topology observation) and partition-homogeneity test with the PAUP software (Farris et al. 1994; Swofford 1991). Each concatenation was investigated for 1,000 replicates. If significant $P$ values $(P<0.01)$ were obtained, the datasets are significantly different and were not combined for analysis. The EzTaxon-e server was used to obtain 16S rRNA sequence similarity values (Kim et al. 2012). Additional gene sequences for the trees were sourced from the GenBank database and added to the genome alignments. The sequence identity was verified by comparative alignment analysis using the BLASTP program from NCBI. Coverage and identity cut-off values were set at 75 and $30 \%$, respectively, for reliable homolog identification.

\section{Homologous gene identification for gene identity comparisons.}

To find gene homologs for the nod and nif/fix genes of interest, the BLASTP algorithm in the JGI IMG Expert Review database was used to compare amino acid sequences of genes across the selected genomes. Moreover, a Python script was developed to extract the percentage of gene identity, the associated e-value, and the orthology notation from the IMG BLASTP results. The initial BLASTP searches were constrained to e-values $\leq 10^{-2}$ and sequence identities $\geq 30 \%$, with the exception of a few genes that showed meaningful homology at lower percentages (Maymon et al. 2015). The final results were filtered to an e-value of $<10^{-7}$, and multiple genes from the same genome were frequently identified as homologous to the query gene. In those cases, the results with the lowest e-value were selected, even if other results had higher gene sequence identity. When no gene match was discovered for a genome, those absent genes were designated as n.d. (not detected). All of the query genes are from the B. tuberum STM678 genome, except nod $H$, which belongs to Burkholderia sp. strain CCGE1002. Each of the 22 genes was searched against the investigated genomes selected for this analysis. The nitrogen fixation genes analyzed included a curated set of 14 nif genes, 13 fix genes, and two nitrogen fixation-related genes, i.e., a $f d x$ gene and the hesB/yadR/yfhF gene, which encodes an iron-sulfur cluster assembly protein.

Each gene family member is depicted in Figures 1 through 6 by a color family. Any gene that is $\geq 50 \%$ identical to the B. tuberum query gene is indicated by different shades of orange; the darker the color, the greater the identity. Genes with an identity lower than $50 \%$ are marked in the color of the family to which they belong.

\section{ACKNOWLEDGMENTS}

The authors thank A. Willems (BCCM/LMG, University of Gent, Belgium), E. Fabiano (IIBCE, Uruguay), L. Moulin (Institut de Recherche pour le Développement and Laboratory of Tropical and Mediterranean Symbioses, Montpellier, France), M. Parker (State University of New York), and J. P. Young (University of York, U.K.) for their participation in the GEBA-RNB project. Gratitude is also extended to people who donated strains: S.M. de Faria (Embrapa, Brasília, Brazil), and the late J. CaballeroMellado, and also the people who manually annotated the B. tuberum STM678 ${ }^{\mathrm{T}}$ and free-living Burkholderia genomes: S. Yerrapragada (Baylor College of Medicine, Houston, TX, U.S.A.), S. Kano (UCLA, Los Angeles, CA, U.S.A.), N. Song (UCLA), and P. Yang (UCLA). L. Perin and V. M. Reis (Embrapa, Brazil), and F. D. Dakora (Tshwane University, Pretoria, South Africa) are thanked for helpful information regarding $B$. silvatlantica SRMrh $20^{\mathrm{T}}$ and B. tuberum STM678 ${ }^{\mathrm{T}}$, respectively. We are grateful to E. Veliz for his comments on the figures. Special thanks to N. Kyrpides (JGI) for facilitating and supporting the GEBA-RNB project from W. Reeve (CRS Australia, Victoria). This research was supported in part by National Science Foundation (NSF) IOB-0537497 to G. Weinstock and A. M. Hirsch as well as NSF IOS-1201735 and a Shanbrom Family Foundation grant to A. M. Hirsch and, also, by Meat and Livestock Australia/Australian Wool Innovations BPSP0013 to J. Howieson and Australian Research Council LP150100848 to S. De Meyer. Additional funding came from a postdoctoral fellowship awarded to P. MartínezHidalgo from "Fundación Ramón Areces" (Spain) and from a L'Oréal USA For Women in Science Fellowship to C. M. Agapaka. The genomics work was performed through the IMG Expert Review website of the United States Department of Energy Joint Genome Institute, a Department of Energy Office of Science User Facility, which is supported under contract number DE-AC02-05CH11231.

\section{LITERATURE CITED}

Angus, A. A., Lee, A., Lum, M. R., Shehayeb, M., Hessabi, R., Fujishige, N. A., Yerrapragada, S., Kano, S., Song, N., Yang, P., Estrada de los Santos, P., de Faria, S. M., Dakora, F. D., Weinstock, G., and Hirsch, A. M. 2013. Nodulation and effective nitrogen fixation of Macroptilium atropurpureum (siratro) by Burkholderia tuberum, a nodulating and plant growth promoting beta-proteobacterium, are influenced by environmental factors. Plant Soil 369:543-562.

Aoki, S., Ito, M., and Iwasaki, W. 2013. From $\beta$ - to $\alpha$-proteobacteria: The origin and evolution of rhizobial nodulation genes nodIJ. Mol. Biol. Evol. 30:2494-2508.

Arigoni, F., Kaminski, P. A., Hennecke, H., and Elmerich, C. 1991. Nucleotide sequence of the fix $A B C$ region of Azorhizobium caulinodans ORS571: Similarity of the fixB product with eukaryotic flavoproteins, characterization of fixX, and identification of nifW. Mol. Gen. Genet. 225:514-520.

Beukes, C. W., Venter, S. N., Law, I. J., Phalane, F. L., and Steenkamp, E. T. 2013. South African papilionoid legumes are nodulated by diverse Burkholderia with unique nodulation and nitrogen-fixation loci. PLoS One 8:e68406.

Bontemps, C., Elliott, G. N., Simon, M. F., Dos Reis Júnior, F. B., Gross, E., Lawton, R. C., Neto, N. E., de Fátima Loureiro, M., De Faria, S. M., Sprent, J. I., James, E. K., and Young, J. P. W. 2010. Burkholderia species are ancient symbionts of legumes. Mol. Ecol. 19:44-52.

Bontemps, C., Rogel, M. A., Wiechmann, A., Mussabekova, A., Moody, S., Simon, M. F., Moulin, L., Elliott, G. N., Lacercat-Didier, L., Dasilva, C., Grether, R., Camargo-Ricalde, S. L., Chen, W., Sprent, J. I., MartínezRomero, E., Young, J. P. W., and James, E. K. 2016. Endemic Mimosa species from Mexico prefer alphaproteobacterial rhizobial symbionts. New Phytol. 209:319-333. 
Boone, C. M., Olsthoorn, M. M., Dakora, F. D., Spaink, H. P., and ThomasOates, J. E. 1999. Structural characterisation of lipo-chitin oligosaccharides isolated from Bradyrhizobium aspalati, microsymbionts of commercially important South African legumes. Carbohydr. Res. 317: 155-163.

Bournaud, C., de Faria, S. M., dos Santos, J. M. F., Tisseyre, P., Silva, M., Chaintreuil, C., Gross, E., James, E. K., Prin, Y., and Moulin, L. 2013. Burkholderia species are the most common and preferred nodulating symbionts of the Piptadenia group (tribe Mimoseae). PLoS One 8: e63478.

Broughton, W. J., Jabbouri, S., and Perret, X. 2000. Keys to symbiotic harmony. J. Bacteriol. 182:5641-5652.

Chen, W. M., de Faria, S. M., Chou, J. H., James, E. K., Elliott, G. N., Sprent, J. I., Bontemps, C., Young, J. P. W., and Vandamme, P. 2008. Burkholderia sabiae sp. nov., isolated from root nodules of Mimosa caesalpiniifolia. Int. J. Syst. Evol. Microbiol. 58:2174-2179.

Chen, W. M., de Faria, S. M., James, E. K., Elliott, G. N., Lin, K. Y., Chou, J. H., Sheu, S. Y., Cnockaert, M., Sprent, J. I., and Vandamme, P. 2007. Burkholderia nodosa sp. nov., isolated from root nodules of the woody Brazilian legumes Mimosa bimucronata and Mimosa scabrella. Int. J. Syst. Evol. Microbiol. 57:1055-1059.

Chen, W. M., de Faria, S. M., Straliotto, R., Pitard, R. M., Simões-Araùjo, J. L., Chou, J. H., Chou, Y. J., Barrios, E., Prescott, A. R., Elliott, G. N., Sprent, J. I., Young, J. P. W., and James, E. K. 2005. Proof that Burkholderia strains form effective symbioses with legumes: A study of novel Mimosa-nodulating strains from South America. Appl. Environ. Microbiol. 71:7461-7471.

Chen, W. M., James, E. K., Coenye, T., Chou, J. H., Barrios, E., de Faria, S. M., Elliott, G. N., Sheu, S. Y., Sprent, J. I., and Vandamme, P. 2006. Burkholderia mimosarum sp. nov., isolated from root nodules of Mimosa spp. from Taiwan and South America. Int. J. Syst. Evol. Microbiol. 56: 1847-1851.

Chen, W.-M., James, E. K., Prescott, A. R., Kierans, M., and Sprent, J. I. 2003a. Nodulation of Mimosa spp. by the $\beta$-proteobacterium Ralstonia taiwanensis. Mol. Plant-Microbe Interact 16:1051-1061.

Chen, W. M., Laevens, S., Lee, T. M., Coenye, T., De Vos, P., Mergeay, M., and Vandamme, P. 2001. Ralstonia taiwanensis sp. nov., isolated from root nodules of Mimosa species and sputum of a cystic fibrosis patient. Int. J. Syst. Evol. Microbiol. 51:1729-1735.

Chen, W. M., Moulin, L., Bontemps, C., Vandamme, P., Béna, G., and Boivin-Masson, C. 2003b. Legume symbiotic nitrogen fixation by betaproteobacteria is widespread in nature. J. Bacteriol. 185:7266-7272.

Corpet, F. 1988. Multiple sequence alignment with hierarchical clustering. Nucleic Acids Res. 16:10881-10890.

Cosseau, C., and Batut, J. 2004. Genomics of the $c c o N O Q P$-encoded $c b b 3$ oxidase complex in bacteria. Arch. Microbiol. 181:89-96.

Curatti, L., Hernandez, J. A., Igarashi, R. Y., Soboh, B., Zhao, D., and Rubio, L. M. 2007. In vitro synthesis of the iron-molybdenum cofactor of nitrogenase from iron, sulfur, molybdenum, and homocitrate using purified proteins. Proc. Natl. Acad. Sci. U.S.A. 104:17626-17631.

De Meyer, S. E., Cnockaert, M., Ardley, J. K., Maker, G., Yates, R., Howieson, J. G., and Vandamme, P. 2013b. Burkholderia sprentiae sp. nov., isolated from Lebeckia ambigua root nodules. Int. J. Syst. Evol. Microbiol. 63:3950-3957.

De Meyer, S. E., Cnockaert, M., Ardley, J. K., Trengove, R. D., Garau, G., Howieson, J. G., and Vandamme, P. 2013a. Burkholderia rhynchosiae sp. nov., isolated from Rhynchosia ferulifolia root nodules. Int. J. Syst. Evol. Microbiol. 63:3944-3949.

De Meyer, S. E., Cnockaert, M., Ardley, J. K., Van Wyk, B.-E., Vandamme, P. A., and Howieson, J. G. 2014. Burkholderia dilworthii sp. nov., isolated from Lebeckia ambigua root nodules. Int. J. Syst. Evol. Microbiol. 64: 1090-1095.

Edgren, T., and Nordlund, S. 2004. The fixABCX genes in Rhodospirillum rubrum encode a putative membrane complex participating in electron transfer to nitrogenase. J. Bacteriol. 186:2052-2060.

Ekici, S., Pawlik, G., Lohmeyer, E., Koch, H.-G., and Daldal, F. 2012. Biogenesis of $c b b 3$-type cytochrome c oxidase in Rhodobacter capsulatus. BBA-Bioenergetics 1817:898-910.

Elliott, G. N., Chen, W. M., Bontemps, C., Chou, J. H., Young, J. P. W., Sprent, J. I., and James, E. K. 2007a. Nodulation of Cyclopia spp. (Leguminosae, Papilionoideae) by Burkholderia tuberum. Ann. Bot. (Lond.) 100:1403-1411.

Elliott, G. N., Chen, W. M., Chou, J. H., Wang, H. C., Sheu, S. Y., Perin, L., Reis, V. M., Moulin, L., Simon, M. F., Bontemps, C., Sutherland, J. M., Bessi, R., de Faria, S. M., Trinick, M. J., Prescott, A. R., Sprent, J. I., and James, E. K. 2007b. Burkholderia phymatum is a highly effective nitrogen-fixing symbiont of Mimosa spp. and fixes nitrogen ex planta. New Phytol. 173:168-180.
Farris, J. S., Källersjö, M., Kluge, A. G., and Bult, C. 1994. Testing significance of incongruence. Cladistics 10:315-319.

Felsenstein, J. 1981. Evolutionary trees from DNA sequences: a maximum likelihood approach. J. Mol. Evol. 17:368-376.

Foussard, M., Garnerone, A.-M., Ni, F., Soupène, E., Boistard, P., and Batut, J. 1997. Negative autoregulation of the Rhizobium meliloti fixK gene is indirect and requires a newly identified regulator, FixT. Mol. Microbiol. 25:27-37.

Garau, G., Yates, R. J., Deiana, P., and Howieson, J. G. 2009. Novel strains of nodulating Burkholderia have a role in nitrogen fixation with papilionoid herbaceous legumes adapted to acid, infertile soils. Soil Biol. Biochem. 41:125-134.

Gyaneshwar, P., Hirsch, A. M., Moulin, L., Chen, W. M., Elliott, G. N., Bontemps, C., Estrada-de Los Santos, P., Gross, E., Dos Reis, F. B., Sprent, J. I., Young, J. P. W., and James, E. K. 2011. Legume-nodulating Betaproteobacteria: diversity, host range, and future prospects. Mol. Plant-Microbe Interact 24:1276-1288.

Howieson, J. G., De Meyer, S. E., Vivas-Marfisi, A., Ratnayake, S., Ardley, J. K., and Yates, R. J. 2013. Novel Burkholderia bacteria isolated from Lebeckia ambigua-A perennial suffrutescent legume of the fynbos. Soil Biol. Biochem. 60:55-64.

Howieson, J. G., Yates, R. J., Foster, K., Real, D., and Besier, B. 2008. Prospects for the future use of legumes. Pages 363-394 in: Leguminous Nitrogen-Fixing Symbioses. M. J. Dilworth, E. K. James, J. I. Sprent, and W. E. Newton, eds. Elsevier, London, U.K.

Juty, N. S., Moshiri, F., Merrick, M., Anthony, C., and Hill, S. 1997. The Klebsiella pneumoniae cytochrome $b d$ ' terminal oxidase complex and its role in microaerobic nitrogen fixation. Microbiology 143:2673-2683.

Kaminski, P. A., Kitts, C. L., Zimmerman, Z., and Ludwig, R. A. 1996. Azorhizobium caulinodans uses both cytochrome bd (quinol) and cytochrome cbb3 (cytochrome c) terminal oxidases for symbiotic N2 fixation. J. Bacteriol. 178:5989-5994.

Kelly, M. J. S., Poole, R. K., Yates, M. G., and Kennedy, C. 1990. Cloning and mutagenesis of genes encoding the cytochrome $b d$ terminal oxidase complex in Azotobacter vinelandii: Mutants deficient in the cytochrome $d$ complex are unable to fix nitrogen in air. J. Bacteriol. 172:6010-6019.

Kim, O.-S., Cho, Y.-J., Lee, K., Yoon, S.-H., Kim, M., Na, H., Park, S.-C., Jeon, Y. S., Lee, J.-H., Yi, H., Won, S., and Chun, J. 2012. Introducing EzTaxon-e: A prokaryotic 16S rRNA gene sequence database with phylotypes that represent uncultured species. Int. J. Syst. Evol. Microbiol. 62:716-721.

Klonowska, A., Chaintreuil, C., Tisseyre, P., Miché, L., Melkonian, R., Ducousso, M., Laguerre, G., Brunel, B., and Moulin, L. 2012. Biodiversity of Mimosa pudica rhizobial symbionts (Cupriavidus taiwanensis, Rhizobium mesoamericanum) in New Caledonia and their adaptation to heavy metal-rich soils. FEMS (Fed. Eur. Microbiol. Soc.) Microbiol. Ecol. 81:618-635.

Kneip, C., Lockhart, P., Voss, C., and Maier, U. G. 2007. Nitrogen fixation in eukaryotes-New models for symbiosis. BMC Evol. Biol. 7:55.

Lemaire, B., Dlodlo, O., Chimphango, S., Stirton, C., Schrire, B., Boatwright, J. S., Honnay, O., Smets, E., Sprent, J., James, E. K., and Muasya, A. M. 2015b. Symbiotic diversity, specificity and distribution of rhizobia in native legumes of the Core Cape Subregion (South Africa). FEMS (Fed. Eur. Microbiol. Soc.) Microbiol. Ecol. 91:1-17.

Lemaire, B., Van Cauwenberghe, J., Chimphango, S., Stirton, C., Honnay, O., Smets, E., and Muasya, A. M. 2015a. Recombination and horizontal transfer of nodulation and ACC deaminase $(a c d S)$ genes within Alphaand Betaproteobacteria nodulating legumes of the Cape Fynbos biome. FEMS (Fed. Eur. Microbiol. Soc.) Microbiol. Ecol. 91:fiv118.

Lemaire, B., Van Cauwenberghe, J., Verstraete, B., Chimphango, S., Stirton, C., Honnay, O., Smets, E., Sprent, J., James, E. K., and Muasya, A. M. 2016. Characterization of the papilionoid-Burkholderia interaction in the Fynbos biome: The diversity and distribution of betarhizobia nodulating Podalyria calyptrata (Fabaceae, Podalyrieae). Syst. Appl. Microbiol. 39:41-48.

Lessie, T. G., Hendrickson, W., Manning, B. D., and Devereux, R. 1996. Genomic complexity and plasticity of Burkholderia cepacia. FEMS (Fed. Eur. Microbiol. Soc.) Microbiol. Lett. 144:117-128.

Liu, W. Y., Ridgway, H. J., James, T. K., James, E. K., Chen, W.-M., Sprent, J. I., Young, J. P., and Andrews, M. 2014. Burkholderia sp. induces functional nodules on the South African invasive legume Dipogon lignosus (Phaseoleae) in New Zealand soils. Microb. Ecol. 68:542-555.

Liu, X., Wei, S., Wang, F., James, E. K., Guo, X., Zagar, C., Xia, L. G., Dong, X., and Wang, Y. P. 2012. Burkholderia and Cupriavidus spp. are the preferred symbionts of Mimosa spp. in southern China. FEMS (Fed. Eur. Microbiol. Soc.) Microbiol. Ecol. 80:417-426.

López-Guerrero, M. G., Ormeño-Orrillo, E., Acosta, J. L., Mendoza-Vargas, A., Rogel, M. A., Ramírez, M. A., Rosenblueth, M., Martínez-Romero, J., 
and Martínez-Romero, E. 2012. Rhizobial extrachromosomal replicon variability, stability and expression in natural niches. Plasmid 68:149-158.

Martínez-Aguilar, L., Díaz, R., Peña-Cabriales, J. J., Estrada-de Los Santos, P., Dunn, M. F., and Caballero-Mellado, J. 2008. Multichromosomal genome structure and confirmation of diazotrophy in novel plantassociated Burkholderia species. Appl. Environ. Microbiol. 74:4574-4579.

Maymon, M., Martínez-Hidalgo, P., Tran, S. S., Ice, T., Craemer, K., Anbarchian, T., Sung, T., Hwang, L. H., Chou, M., Fujishige, N. A., Villella, W., Ventosa, J., Sikorski, J., Sanders, E. R., Faull, K. F., and Hirsch, A. M. 2015. Mining the phytomicrobiome to understand how bacterial coinoculations enhance plant growth. Front. Plant Sci. 6: 00784.

Mishra, R. P. N., Tisseyre, P., Melkonian, R., Chaintreuil, C., Miché, L., Klonowska, A., Gonzalez, S., Bena, G., Laguerre, G., and Moulin, L. 2012. Genetic diversity of Mimosa pudica rhizobial symbionts in soils of French Guiana: Investigating the origin and diversity of Burkholderia phymatum and other beta-rhizobia. FEMS (Fed. Eur. Microbiol. Soc.) Microbiol. Ecol. 79:487-503.

Moulin, L., Munive, A., Dreyfus, B., and Boivin-Masson, C. 2001. Nodulation of legumes by members of the beta-subclass of Proteobacteria. Nature 411:948-950.

Ormeño-Orrillo, E., Rogel, M. A., Chueire, L. M. O., Tiedje, J. M., Martínez-Romero, E., and Hungria, M. 2012. Genome sequences of Burkholderia sp. strains CCGE1002 and H160, isolated from legume nodules in Mexico and Brazil. J. Bacteriol. 194:6927.

Parker, M. A. 2015. A single sym plasmid type predominates across diverse chromosomal lineages of Cupriavidus nodule symbionts. Syst. Appl. Microbiol. 38:417-423.

Parkhill, J., Wren, B. W., Mungall, K., Ketley, J. M., Churcher, C., Basham, D., Chillingworth, T., Davies, R. M., Feltwell, T., Holroyd, S., Jagels, K., Karlyshev, A. V., Moule, S., Pallen, M. J., Penn, C. W., Quail, M. A., Rajandream, M. A., Rutherford, K. M., van Vliet, A. H., Whitehead, S., and Barrell, B. G. 2000. The genome sequence of the food-borne pathogen Campylobacter jejuni reveals hypervariable sequences. Nature 403:665-668.

Perin, L., Martínez-Aguilar, L., Paredes-Valdez, G., Baldani, J. I., Estradade Los Santos, P., Reis, V. M., and Caballero-Mellado, J. 2006. Burkholderia silvatlantica sp. nov., a diazotrophic bacterium associated with sugar cane and maize. Int. J. Syst. Evol. Microbiol. 56:1931-1937.

Perret, X., Staehelin, C., and Broughton, W. J. 2000. Molecular basis of symbiotic promiscuity. Microbiol. Mol. Biol. Rev. 64:180-201.

Pitcher, R. S., and Watmough, N. J. 2004. The bacterial cytochrome $c b b 3$ oxidases. Biochimica et Biophysica Acta (BBA) -. Bioenergetics 1655:388-399.

Reeve, W., Ardley, J., Tian, R., Eshragi, L., Yoon, J. W., Ngamwisetkun, P., Seshadri, R., Ivanova, N. N., and Kyrpides, N. C. 2015. A genomic encyclopedia of the root nodule bacteria: Assessing genetic diversity through a systematic biogeographic survey. Stand. Genomic Sci. 10:14.

Sheu, S.-Y., Chen, M.-H., Liu, W. Y. Y., Andrews, M., James, E. K., Ardley, J. K., De Meyer, S. E., James, T. K., Howieson, J. G., Coutinho, B. G., and Chen, W.-M. 2015. Burkholderia dipogonis sp. nov., isolated from root nodules of Dipogon lignosus in New Zealand and Western Australia. Int. J. Syst. Evol. Microbiol. 65:4716-4723.

Sheu, S. Y., Chou, J. H., Bontemps, C., Elliott, G. N., Gross, E., dos Reis Junior, F. B., Melkonian, R., Moulin, L., James, E. K., Sprent, J. I., Young, J. P., and Chen, W. M. 2013. Burkholderia diazotrophica sp. nov., isolated from root nodules of Mimosa spp. Int. J. Syst. Evol. Microbiol. 63:435-441.

Sheu, S.-Y., Chou, J.-H., Bontemps, C., Elliott, G. N., Gross, E., James, E. K., Sprent, J. I., Young, J. P. W., and Chen, W.-M. 2012. Burkholderia symbiotica sp. nov., isolated from root nodules of Mimosa spp. native to north-east Brazil. Int. J. Syst. Evol. Microbiol. 62:2272-2278.

Swofford, D. L. 1991. PAUP: Phylogenetic Analysis Using Parsimony, version 3.1. Smithsonian Institution, Washington, DC.

Tamura, K., Stecher, G., Peterson, D., Filipski, A., and Kumar, S. 2013. MEGA6: Molecular evolutionary genetics analysis version 6.0. Mol. Biol. Evol. 30:2725-2729.

Tsai, M. H., and Saier, M. H., Jr. 1995. Phylogenetic characterization of the ubiquitous electron transfer flavoprotein families ETF- $\alpha$ and ETF- $\beta$. Res. Microbiol. 146:397-404.

Vandamme, P., Goris, J., Chen, W. M., de Vos, P., and Willems, A. 2002. Burkholderia tuberum sp. nov. and Burkholderia phymatum sp. nov. nodulate the roots of tropical legumes. Syst. Appl. Microbiol. 25:507512.

Varghese, N. J., Mukherjee, S., Ivanova, N., Konstantinidis, K. T., Mavrommatis, K., Kyrpides, N. C., and Pati, A. 2015. Microbial species delineation using whole genome sequences. Nucleic Acids Res. 43: 6761-6771.

Walker, R., Watkin, E., Tian, R., Bräu, L., O’Hara, G., Goodwin, L., Han, J., Lobos, E., Huntemann, M., Pati, A., Woyke, T., Mavromatis, K., Markowitz, V., Ivanova, N., Kyrpides, N., and Reeve, W. 2014a. Genome sequence of the acid-tolerant Burkholderia sp. strain WSM2230 from Karijini National Park, Australia. Stand. Genomic Sci. 9:551-561.

Walker, R., Watkin, E., Tian, R., Bräu, L., O’Hara, G., Goodwin, L., Han, J., Reddy, T., Huntemann, M., Pati, A., Woyke, T., Mavromatis, K., Markowitz, V., Ivanova, N., Kyrpides, N., and Reeve, W. 2014b. Genome sequence of the acid-tolerant Burkholderia sp. strain WSM2232 from Karijini National Park, Australia. Stand. Genomic Sci. 9:1168-1180.

Wang, D., Yang, S., Tang, F., and Zhu, H. 2012. Symbiosis specificity in the legume: Rhizobial mutualism. Cell. Microbiol. 14:334-342.

\section{AUTHOR-RECOMMENDED INTERNET RESOURCES}

GenBank database: http://www.ncbi.nlm.nih.gov

Joint Genome Institute (JGI) website: https://img.jgi.doe.gov/cgi-bin/mer/main.cgi

The JGI/IMG genomic database: https://img.jgi.doe.gov/cgi-bin/m/main.cgi?section=FindGenesBlast\&page= geneSearch\%20Blast

NCBI BLAST database: https://blast.ncbi.nlm.nih.gov/Blast.cgi 